\title{
A comparison of oceanic skin effect parameterizations using shipborne radiometer data
}

\author{
Elizabeth C. Kent, Thomas N. Forrester, and Peter K. Taylor \\ James Rennell Division, Southampton Oceanography Centre, Southampton, England
}

\begin{abstract}
Sea surface temperature data from a shipborne radiometer were used to assess the thermal skin effect parameterization schemes of Saunders [1967], Hasse [1971], Schliussel et al. [1990], and Soloviev and Schliussel [1994]. Under low-wind, high-insolation conditions, the presence of a near surface thermocline resulted in an apparent skin effect which depended on the history of the surface heating. Neglecting these cases, the Saunders [1967] and other schemes which omit solar radiation were the most effective. The observed variation with wind speed of the adjustable coefficient, $\lambda_{s}$, in the Saunders formulae was similar to that predicted by Soloviev and Schlüssel [1994], but the values were significantly higher, resulting in a greater magnitude of the observed skin effect. For the conditions occurring in this data set the better formulae predicted the skin effect with a standard deviation of $\pm 0.16^{\circ} \mathrm{C}$ compared to a variation of the observed skin effect of nearly $\pm 0.3^{\circ} \mathrm{C}$.
\end{abstract}

\section{Introduction}

A better understanding of the vertical gradient of temperature just beneath the sea surface would lead to more accurate estimates of the air-sea fluxes of sensible and latent heat (see, for example, Liu et al. [1979]). The difference in temperature between the surface skin of the ocean and the subsurface water is also an important factor if radiometric measurements of sea surface temperature (SST) from satellite borne infrared radiometers are to be combined with in situ data. In their review paper of this thermal skin effect, Robinson et al. [1984] suggest that SST data are required to within $0.2^{\circ} \mathrm{C}$ (for example, for flux calculations for ocean heat budgets); the skin effect can be larger than this required accuracy and must therefore be taken into account.

After observations of the skin effect were reported by Hasse [1963], Saunders [1967] developed a skin effect formula (described in section 4.1 ) by considering the heat transfer through a viscous boundary layer at a rigid surface. Although he suggested a method for including the effect of the varying absorption of solar radiation with depth, he did not explicitly include it in the model. Hasse [1971] included a solar heating term in a model (section 4.2) which otherwise was similar to that of Saunders. Various studies [e.g., Paulson and Parker, 1972; Grassl, 1976; Paulson and Simpson, 1981] have evaluated the adjustable parameter, $\lambda_{s}$, which occurs in the Saunders formula with encouraging consistency, at least for data obtained at sea rather than in the laboratory. However, when Saunders [1973] reconsidered the problem, he concluded that, since the assumption of a rigid boundary was false, the success of the Saunders [1967] model was probably fortuitous. A different approach, the "surface renewal model" was suggested by Liu and Businger [1975] and Brutsaert [1975]. This was developed by Liu et al. [1979] whose model of the marine atmospheric surface layer included a simple skin effect

Copyright 1996 by the American Geophysical Union.

Paper number $96 \mathrm{JC} 01054$

0148-0227/96/96JC-01054\$09.00 formulation. More recently, Soloviev and Schliussel [1994] have presented a new formulation of the surface renewal model (section 4.4). However, the questionable ability of the Saunders type of model to accurately predict the skin effect under all conditions has lead to statistical treatments [e.g., Schliussel et al., 1990] (described in section 4.3).

Investigations of the skin effect have been limited by the difficulty of measuring the radiometric skin temperature to the necessary accuracy and precision. The many potential sources of error have been discussed by Saunders [1973] and Paulson and Simpson [1981]. Thus, although Robinson et al. [1984] emphasized the need for more skin effect measurements, the number of available data sets still remains small. Using data obtained with a relatively new design of radiometer [Thomas et al., 1995], this paper will compare the performance of four skin effect models: the original Saunders [1967] formula, the Hasse [1971] variation, the statistical model of Schlüssel et al. [1990], and the Soloviev and Schlïssel [1994] surface renewal model. The meteorological observations to be used were obtained during the Surface of the Ocean, Fluxes, and Interaction with the Atmosphere (SOFIA) experiment and will be described in section 2 . Because accurate radiometric measurements are difficult, section 3 describes in detail the radiometric observations and the processing used. Section 4 describes and compares the chosen skin effect models, with the results presented in section 5 and the comparison between the results for the different formulae discussed in section 6 . The summary and conclusions are presented in section 7 .

\section{Meteorological Data}

\subsection{SOFIA Experiment}

The data used in this study were collected on the Insitut Francais de Recherche pour l'Exploitation de la Mer ship N.O. Le Suroit during the SOFIA experiment. The cruise took place between May 31, and June 20,1992, in a region south of Sao Miguel in the Azores (between $34^{\circ}$ to $38^{\circ} \mathrm{N}$ and $22^{\circ}$ to $27^{\circ} \mathrm{W}$ ). SOFIA was part of the Atlantic Stratocumulus Transition Experiment. Figure 1 shows the cruise track for the 


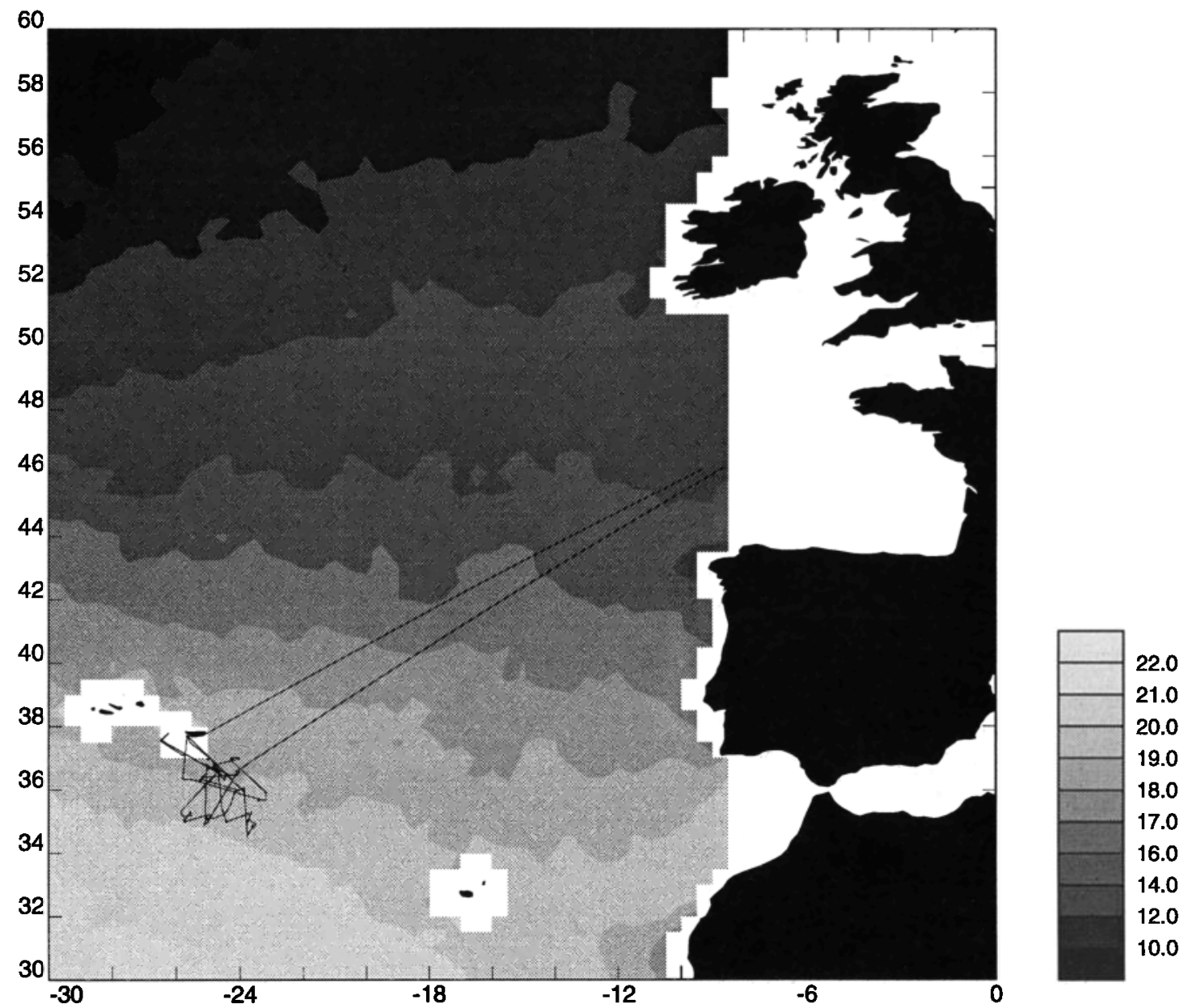

Figure 1. Cruise track for the SOFIA experiment overlaid on the mean SST field for June from advanced very high resolution radiometer data between 1982 and 1993.

experiment, overlaid on the mean June SST field from the advanced very high resolution radiometer (AVHRR) data between 1982 and 1993. The region was chosen because it has a rich diversity of boundary layer clouds at differing heights accompanied by steady winds. The experiment combined aircraft, ship, buoy, and satellite observations.

\subsection{Mean Meteorological Variables}

Details of the instrumentation used on Le Suroit are given by Kent and Pascal [1992]. Mean meteorological parameters and SST were recorded as $1-$ min means (based on $1-\mathrm{Hz}$ sampling) except for the wind speed which was a 15-min vector average from a sonic anemometer. The $15-\mathrm{min}$ wind speeds were interpolated to give 1 -min averages after combination with data logged from the ship's navigation system to provide true wind speeds.

One-minute average SST was measured using a trailing thermistor designed to give near-surface data. Figure 2 shows the thermistor assembly which was located at the end of a buoyant cable which had been weighted to measure the temperature at shallow depths. The cable was deployed from a horizontal boom mounted on the starboard side of the port foredeck just aft of the SST radiometer location. With the ship moving forward at cruising speed, the $20-\mathrm{m}$ cable trailed aft and the thermistor was positioned several meters aft of the radiometer field of view at a depth of about $0.1 \mathrm{~m}$ or less. When the ship was stopped in the water the thermistor tended to sink to about 1 to $3 \mathrm{~m}$, becoming more nearly beneath the radiometer position. Most of the data used here were obtained with the ship moving slowly forward at about $1 \mathrm{~m} \mathrm{~s}^{-1}$, in which case a thermistor depth between $0.1 \mathrm{~m}$ to $1 \mathrm{~m}$ was typical. Frequent measurements of bulk SST were also made using an insulated United Kingdom Meteorological Office type SST bucket and thermometer. These bucket measurements showed that the calibration of the thermistor sensors drifted with time before the sensor eventually failed. This was probably due to water leakage into the sensor housing. For this paper we have only used the data from the first thermistor to be deployed. This operated throughout the 16 days of the first leg of the SOFIA experiment and showed an approximately constant drift of $-0.024^{\circ} \mathrm{C}$ per day, for which we have corrected. During the second leg the sensors failed more rapidly; three had to be used, one failing almost immediately after deployment. Compared to the performance of the first thermistor, the drift and offset of these sensors were significantly greater and the data from the second leg have not been used.

The comparisons between the thermistor and bucket measurements showed no evidence for direct heating of the thermistor by solar radiation. Any correlation with variations 


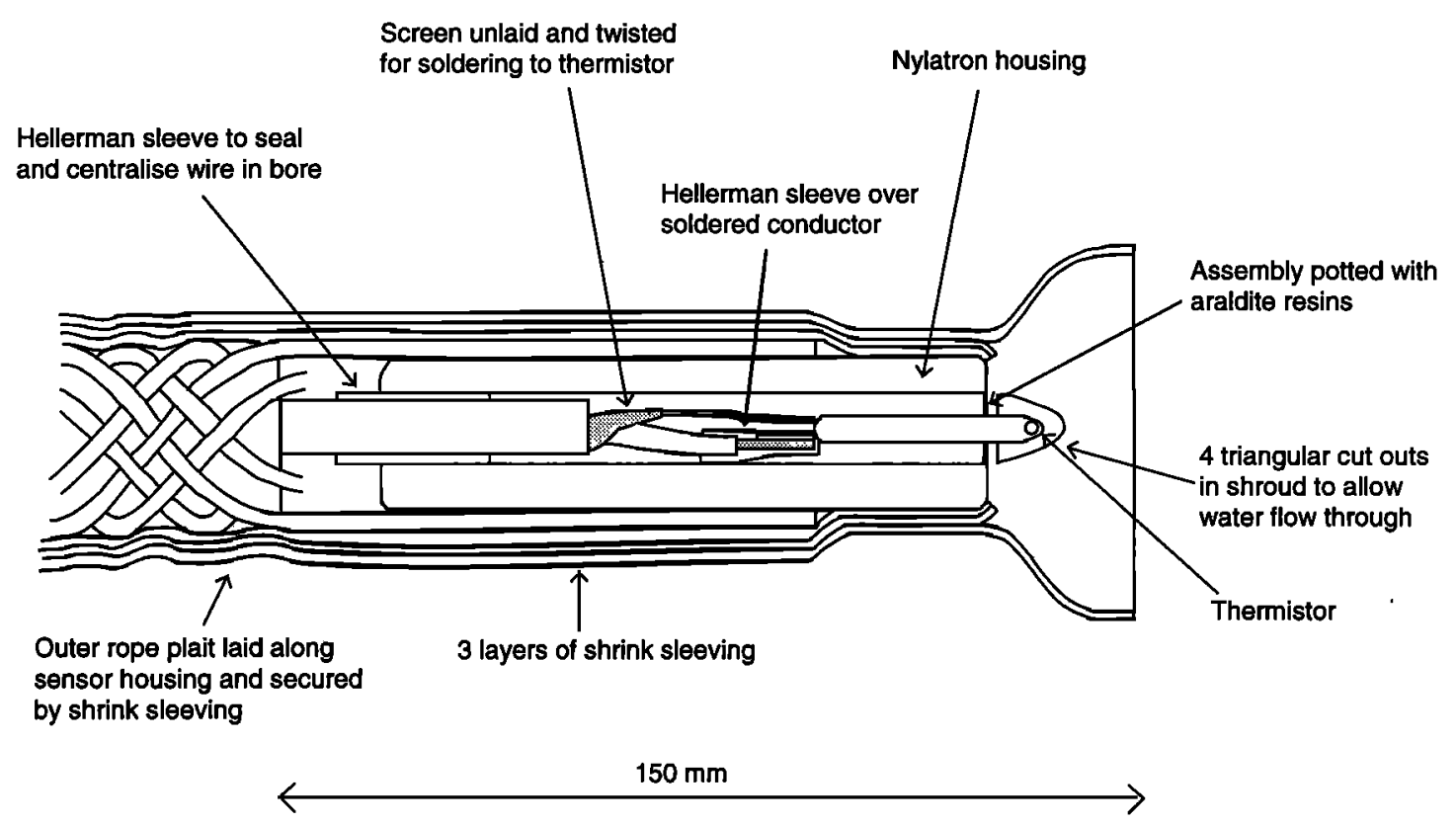

Figure 2. Diagram to show cross section through trailing thermistor used in the SOFIA experiment.

in ship's speed was also sought. There was no evidence for the thermistor reading anomalously cool at higher ship speeds, as might have been expected if the sensor had tended to leave the water. At low ship speeds a few cool thermistor values may have been due to the thermistor sinking into cooler water, if the surface water was stratified by solar heating at the surface. The amount of data thus affected was less than $1 \%$ and did not significantly affect the results presented below.

\subsection{Estimation of the Heat Fluxes}

Incoming shortwave and longwave radiation were logged by a team from Centre de Recherche en Physique de l'Environnement Terrestre et Planétaire using pyranometer and pyrgeometer sensors. Service Mesures eu Altitude (Service des Equipements et des Techniques Instrumentales de la Météorologie) launched radiosondes, the data from which were used in the calculation of effective sky temperatures used in estimating the longwave radiation reflected from the sea surface (see section 3.5). Net shortwave was calculated using the albedos given by Payne [1972] and the net longwave using the formulae for longwave exitance given by Lind and Katsaros [1984].

Sensible and latent heat fluxes were calculated from the mean meteorological observations using the bulk formulae of Smith [1988, 1989]. These bulk formulae predict the heat fluxes and stability using the bulk SST value, even though the skin temperature is the physically correct quantity. Only Liu et al. [1979] provide bulk formulae for use with the skin temperature, and their transfer coefficients depend on the form assumed for the neutral drag coefficient. The Smith [1988] formulation has been chosen in preference to Liu et al. [1979] because it includes the results of more recent experiments.

The use of bulk formula based flux estimates will inevitably have introduced some noise into the evaluations presented here; however, Paulson and Simpson [1981] demonstrated that the error would be small, and this can be confirmed for our data as follows. Our results will show that the best parameterization will relate the skin effect to the cooling fluxes and the wind stress. The slope of this relationship for a typical wind speed of $5 \mathrm{~m} \mathrm{~s}^{-1}$ implies that, to estimate the skin effect to $0.1^{\circ} \mathrm{C}$, the fluxes must be accurate to within about $40 \mathrm{~W} \mathrm{~m}^{-2}$. For comparison, the likely error in the flux values must be estimated. The largest error in the longwave flux will probably be due to the radiometer error. The radiometer was calibrated immediately before the cruise, and there is no other reliable source of validation. It is assumed accurate to $5 \%$, which leads to a maximum error in the downwelling longwave flux of $20 \mathrm{~W} \mathrm{~m}^{-2}$. Errors in the upwelling longwave flux are assumed to be much smaller than this error. The error in the solar flux is also assumed to be about $5 \%$, a maximum of about $50 \mathrm{~W} \mathrm{~m}^{-2}$; however, the shortwave flux was found not to be critical in this study. The bulk formulae are usually assumed to give the sensible and latent fluxes to better than $20 \%$. Combining this with an estimated error of $0.1^{\circ} \mathrm{C}$ in the air and dew point temperatures, $0.2^{\circ} \mathrm{C}$ in the SST and $0.2 \mathrm{~m} \mathrm{~s}^{-1}$ in the wind speed gives an approximate error in the sensible heat flux of $23 \%$ and in the latent heat flux of $25 \%$. This leads to a maximum error for the total cooling flux (sensible plus latent plus net longwave) of $32 \mathrm{~W} \mathrm{~m}^{-2}$ for maximum flux values, and a more typical estimate for average flux values of $16 \mathrm{~W} \mathrm{~m}^{-2}$. The most likely error in an estimate of the skin effect due to errors in our flux estimates would therefore be about $0.04^{\circ} \mathrm{C}$.

Some parameterizations require a value for the wind stress or equivalently for the friction velocity, $u_{*}$. This has been estimated from the wind speed following Smith [1988]. The friction velocity in water has been calculated from that in air by multiplying by the ratio of the density of air over that of water. The validity of this assumption, which neglects any partition of the wind stress between form and skin drag, will be discussed below (section 6).

\subsection{Conditions at the Time of the Experiment}

Figure 3 shows histograms summarizing the range of meteorological conditions during the first leg of SOFIA. The 

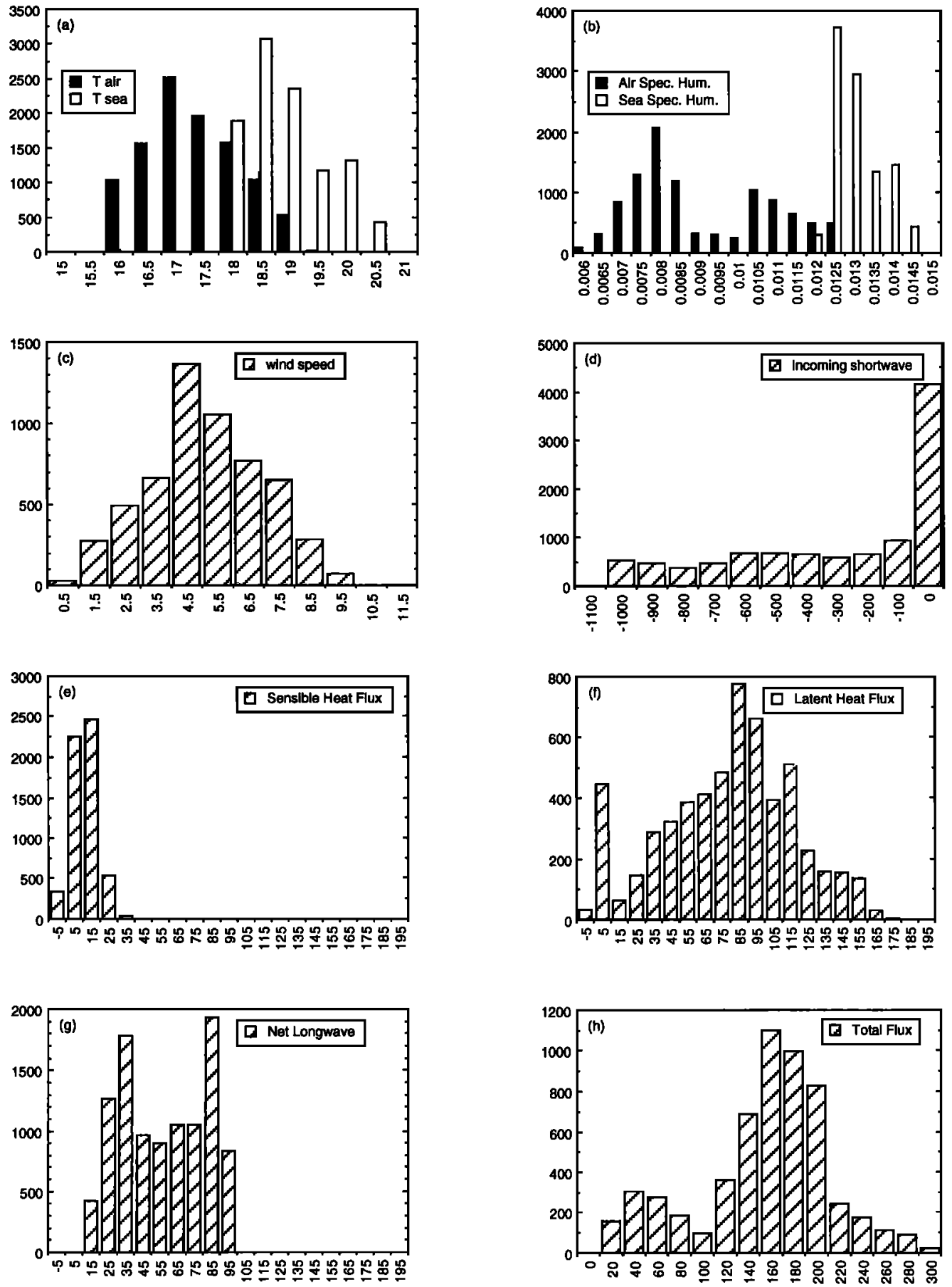

Figure 3. Histograms showing the range of meteorological conditions experienced during the SOFIA experiment: (a) air and sea temperatures, (degrees Celsius); (b) air and sea surface values of the specific humidity, $\left(\mathrm{kg} \mathrm{kg}^{-1}\right)$; (c) wind speed $\left(\mathrm{m} \mathrm{s}^{-1}\right)$; (d) insolation $\left(\mathrm{W} \mathrm{m}^{-2}\right)$; (e) sensible heat flux (W $\left.\mathrm{m}^{-2}\right)$; (f) latent heat flux $\left(\mathrm{W} \mathrm{m}^{-2}\right)$; (g) net longwave $\left(\mathrm{W} \mathrm{m}^{-2}\right)$; (h) sensible + latent + net longwave $\left(\mathrm{W} \mathrm{m}^{-2}\right)$. All fluxes are positive upwards.

experiment straddled the Azores Front with SST (Figure 3a) ranging from $17.8^{\circ} \mathrm{C}$ at the northeast to $20.6^{\circ} \mathrm{C}$ at the southwest in a region of consistently high pressure. Air temperatures were normally significantly colder than the SST; the mean SST-air temperature difference was $1.5^{\circ} \mathrm{C}$. The air and sea surface specific humidity values are shown in Figure $3 b$; the mean specific humidity difference was $3.6 \mathrm{~g} \mathrm{~kg}^{-1}$ (mean relative humidity $78 \%$ ). Winds (Figure $3 \mathrm{c}$ ) were generally light, below $10 \mathrm{~m} \mathrm{~s}^{-1}$.
A similar number of measurements were obtained during day and night periods; the maximum insolation (Figure 3d) being $-1050 \mathrm{~W} \mathrm{~m}^{-2}$ (where all heat fluxes are defined as positive upwards). Mean sensible and latent heat fluxes (Figures $3 e$ and 3f) were 11 and $80 \mathrm{~W} \mathrm{~m}^{-2}$, respectively, with their sum always acting to cool the ocean. The typical net longwave radiation for clear skies was $85 \mathrm{~W} \mathrm{~m}^{-2}$, and for cloudy conditions $30 \mathrm{~W}$ $\mathrm{m}^{-2}$ (Figure $3 \mathrm{~g}$ ). Excluding the insolation, the total surface heat flux (Figure $3 \mathrm{~h}$ ) was always directed from the sea to the air 
with a mean value of $146 \mathrm{~W} \mathrm{~m}^{-2}$, mainly due to the latent heat and net longwave cooling.

\section{Radiometric Data}

\subsection{Description of the Radiometer}

The radiometer was a self-calibrating two-channel type; its design was based on an earlier model described by Hepplewhite [1989], which was developed further at the Rutherford Appleton Laboratory and Satellites International Ltd. (SIL) [Smith, 1991]. It was one of two identical STR 100-1 instruments built simultaneously under contract by SIL, the performance of the other instrument, belonging to the British Antarctic Survey, has been described by Thomas et al. [1995].

The optical path of the pyroelectric detector is deflected between the radiance coming from the target (sea surface) and that from a reference blackbody at a known temperature by a chopper blade, at a frequency of $30 \mathrm{~Hz}$, and by an off-axis parabolic mirror. Thus the detector alternately measures the radiances between the two sources, and the difference is taken. Before the radiance reaches the detector it passes through one of two filters, which are centered on $11-\mu \mathrm{m}$ and $12-\mu \mathrm{m}$ wave bands. These were selected to be similar to that of the along track scanning radiometer flown on the ERS 1 satellite. For the SOFIA data only the $11-\mu \mathrm{m}$ filter was used in order to restrict the number of varying parameters within the data set.

\subsection{Calculation of the Radiometric SST}

The radiance coming from the sea surface which passes through the filter at wavelength $\lambda$ and temperature $T$ is given by the Planck function $B(\lambda, T)$. The radiance intensity $B^{\prime}(T)$, is an integral over the combined spectral response of the band filter and the detector window. The detector signal $S$ can be expressed as a linear function of radiance coming from the sea surface $\left(B^{\prime}\left(T_{w}\right)\right)$, plus the portion of downwelling sky radiance that is reflected into the optical path $\left(B^{\prime}\left(T_{\text {sky }}\right)\right)$ minus the reference blackbody radiance $\left(B^{\prime}\left(T_{R B B}\right)\right)$ where $T_{w}$ is the water temperature, $T_{\text {sky }}$ is the sky temperature and $T_{R B B}$ is the reference blackbody temperature.

$$
\begin{aligned}
S_{W}= & G\left[\varepsilon_{W} B^{\prime}\left(T_{W}\right)+\left(1-\varepsilon_{W}\right) B^{\prime}\left(T_{s k y}\right)-\varepsilon_{B B} B^{\prime}\left(T_{R B B}\right)\right] \\
& +O
\end{aligned}
$$

$\varepsilon_{W}$ is the emissivity of seawater and $\varepsilon_{B B}$ is the emissivity of the reference blackbody; $G$ is the gain and $O$ the offset for the radiometer electronics. Stray radiation which can be emitted or reflected from the inside of the instrument, or changes in ambient temperature, can affect the output signal of the detector. In order to calibrate the signal at frequent intervals, two radiance sources, one at ambient temperature called the cold blackbody (CBB) and one at approximately $8 \mathrm{~K}$ above this, called the hot blackbody (HBB), are alternately moved into the optical path. Each blackbody has an associated platinum resistance thermometer, providing the temperature $T$ from which a radiant intensity is calculated. The calibration blackbodies are identical in construction to the reference blackbody with an emissivity value of 0.995 [Smith, 1991]. For each blackbody there is an associated radiant intensity and detector signal:

$$
\begin{aligned}
& S_{H B B}=G\left[\varepsilon_{B B} B^{\prime}\left(T_{H B B}\right)-\varepsilon_{B B} B^{\prime}\left(T_{R B B}\right)\right]+O \\
& S_{C B B}=G\left[\varepsilon_{B B} B^{\prime}\left(T_{C B B}\right)-\varepsilon_{B B} B^{\prime}\left(T_{R B B}\right)\right]+O
\end{aligned}
$$

from which the gain $(G)$ and offset $(O)$ in (1) can be calculated:

$$
\begin{gathered}
G=\frac{\varepsilon_{B B} B^{\prime}\left(T_{H B B}\right)-\varepsilon_{B B} B^{\prime}\left(T_{C B B}\right)}{S_{H B B}-S_{C B B}} \\
O=\frac{\varepsilon_{B B} B^{\prime}\left(T_{C B B}\right) S_{H B B}-\varepsilon_{B B} B^{\prime}\left(T_{H B B}\right) S_{C B B}}{S_{H B B}-S_{C B B}}
\end{gathered}
$$

Using the known detector and filter response functions, the Rutherford Appleton Laboratory calculated a quadratic approximation to the Planck function over the desired range of temperatures; the coefficients were $\mathrm{a}=2.018502 \times 10^{-3}, \mathrm{~b}=$ -0.6374077 , and $c=54.70953$. Given that $B^{\prime}(T)$ approximates to a quadratic at wave bands near $11 \mu \mathrm{m}$, (1) can then be simplified to

$$
a T_{w}^{2}+b T_{w}+\chi=0
$$

where

$$
\begin{aligned}
\chi= & \varepsilon_{w}^{-1}\left(1-\varepsilon_{w}\right)\left(a T_{s k y}^{2}+b T_{s k y}+c\right)-\left(a T_{R B B}^{2}+b T_{R B B}+c\right) \\
& +\left[\left(O-S_{w}\right) / G\right]
\end{aligned}
$$

Thus, having used the cold and hot blackbody temperatures to calibrate the amplifier gain and offset, calculation of the radiometric SST from the detector signal requires knowledge of the reference blackbody temperature, the emissivity of seawater, and the radiometric sky brightness temperature. The steps in this calculation will be described in the following sections.

\subsection{Calibration of the Radiometer}

Throughout the majority of the cruise the radiometer was controlled remotely from a computer within the ship. This software logged the data and controlled the measurement cycles. Each cycle consisted of a calibration, during which the cold and hot blackbodies were viewed, followed by a period of viewing the sea surface. This process continued every $10 \mathrm{~min}$, and each calibration took approximately $1 \mathrm{~min}$. From initial examination of the data it was observed that anomalous jumps in the determined SST value occurred after some of the calibrations. These jumps occurred often enough to make it impractical to ignore these calibration data. To minimize the error it was found that smoothing the gain and offset (as calculated from (4)) over a period of 1 hour gave the lowest standard deviations.

During SOFIA one attempt was made to calibrate the radiometer by siting it over a stirred bucket containing water of known temperature. For these data the radiometric temperatures, calculated during the cruise, suggested that the radiometer was reading warm by several tenths Kelvin. When the radiometer data had been reprocessed, examination of the nighttime skin effect at small total heat flux also suggested that the radiometric SST was biased too high, by approximately $1.5 \mathrm{~K}$. A similar bias had also been found by Thomas et al. [1995] using the identical twin radiometer to the one used in this survey. The platinum resistance thermometer (PRT) calibration coefficients used were thought to be incorrect due to the calibration procedure adopted by the instrument makers SIL Ltd. The PRT calibrations were undertaken before the complete assembly of the radiometer, so that voltage changes across the PRTs detected by Thomas et al. [1995] were not included in the calibrations. 
Unfortunately, the wiring to the PRTs for the SOFIA instrument had been altered subsequent to the experiment and recalibration of the radiometer would not be useful. We have therefore followed the correction procedure of Thomas et al. [1995]. Their analysis showed that the calibration error resulted in an offset which was reasonably constant over a range of tropical and polar conditions. An incorrect blackbody temperature ( $T_{R B B}$ ) resulting in a difference $\Delta B^{\prime}\left(T_{R B B}^{\prime}\right)$ between the calculated radiance $B^{\prime}\left(T_{R B B}^{\prime}\right)$ and actual radiance can be shown to have a small effect on the gain $(G)$ and offset $(O)$, with the most significant effect in (1). Thus (1) becomes

$$
\begin{aligned}
S_{W}=G\{ & \varepsilon_{W} B^{\prime}\left(T_{W}\right)+\left(1-\varepsilon_{W}\right) B^{\prime}\left(T_{S}\right) \\
& \left.-\left[\varepsilon_{B B^{\prime}} B^{\prime}\left(T_{R B B}^{\prime}\right)-\Delta B^{\prime}\left(T_{R B B}^{\prime}\right)\right]\right\}+O
\end{aligned}
$$

The radiance term $\Delta B^{\prime}\left(T_{R B B}\right)$ was due to an error $\Delta T_{R B B}$ in the temperature from the PRT measurement. This temperature offset $\Delta T_{R B B}$ was not constant owing to the nonlinear relationship between the PRT voltage and temperature. It was therefore assumed that

$$
\Delta T_{R B B}=\gamma T_{R B B}^{\prime} \quad(\gamma<1)
$$

It can then be shown that

$$
\Delta B^{\prime}\left(T_{R B B}^{\prime}\right)=a \gamma(a+2) T_{R B B}^{2}+b \gamma T_{R B B}
$$

where $a$ and $b$ are the coefficients to the quadratic approximation to the Planck function given in section 3.2, and the extra term $\gamma$ was estimated $(\gamma=0.0184)$ by minimizing the difference between stirred bucket radiometric and thermometric water temperature measurements. The addition of the error term gave a radiometric measurement accuracy to within $0.1 \mathrm{~K}$ of the thermometer measurements.

An attempt was made to use existing in situ stirred tank validation measurements taken during the SOFIA cruise to derive a correction coefficient. However, only spot values of the stirred bucket and radiometric temperature were recorded, so it was not possible to reprocess the radiometer data over a complete time series to evaluate this term. Therefore we have incorporated the value of $\gamma$ derived by Thomas et al. [1995]. This was considered to be justified since both radiometers were built at the same time and to identical standards.

\subsection{Emissivity of Seawater}

The total emissivity of seawater is nearly constant for viewing angles up to $45^{\circ}$ normal to the sea surface; beyond this point emissivity decreases rapidly, with a corresponding increase in reflectivity [Saunders, 1967]. The radiometer was mounted on the ship's rail at about $23^{\circ}$ from the normal of the sea surface to give a clear field of view away from the ship. At this angle the main source contributing to the reflections can be assumed to be downward sky radiation reflected directly from the sea surface [Hepplewhite, 1989].

The combined spectral response of the pyroelectric detector and the $11 \mu \mathrm{m}$ filter show a minor leak centered at $20 \mu \mathrm{m}$. A range of wind speed dependent emissivity values were calculated by $R$. Knight from the Rutherford Appleton
Table 1. Emissivity of Seawater at $20^{\circ}$ Incidence Angle, Taking Into Account the Spectral Response of the Radiometer Filter

\begin{tabular}{cl}
\hline Wind Speed, $\mathrm{m} \mathrm{s}^{-1}$ & Emissivity \\
\hline 0 & 0.97665 \\
3 & 0.9764 \\
5 & 0.97625 \\
10 & 0.9758 \\
15 & 0.97535 \\
\hline
\end{tabular}

Laboratory. This was done by convolving the spectral response function with emissivity values taken from the literature (for the 750 - to $1100-\mathrm{cm}^{-1}$ region [Masuda et al., 1988] and for the longwave region [Ray, 1972]). The values given in Table 1 are valid at $290 \mathrm{~K}$, for every $\pm 1 \mathrm{~K}$ change in temperature from that point the value of $1.3 \times 10^{-4}$ must be added or subtracted.

\subsection{Reflected Sky Radiation}

In order to estimate the part of the radiometric signal that originated from reflected longwave infrared sky radiation, an estimation of sky brightness temperature as viewed through the $11-\mu \mathrm{m}$ filter was necessary. Ideally, an identical radiometer should have been mounted looking upward, or at least the radiometer used to periodically view the sky. Unfortunately, the SIL radiometer only had the capability of measuring temperature within a dynamic range of $\pm 25 \mathrm{~K}$ of the reference blackbody temperature and this precluded direct sky temperature measurements. Given the data available from the SOFIA experiment it has been necessary to estimate the sky radiation correction indirectly as follows.

The sky brightness temperature (at a similar wavelength to the $11-\mu \mathrm{m}$ filter in the radiometer) was estimated by using a radiative transference model [Zavody et al., 1995] applied to atmospheric temperature and humidity profiles taken from radiosonde measurements made every 6 hours during the cruise. To interpolate between these times, the estimated sky brightness temperatures were regressed against downwelling infrared measurements taken from a broadband pyrgeometer, giving the following relationship:

$$
T_{s k y}=109.50+[0.30 * I R]
$$

where $T_{s k y}(\mathrm{~K})$ is the sky temperature data averaged to $10-\mathrm{min}$ means and $I R$ is the downwelling infrared radiation $\left(\mathrm{W} \mathrm{m}^{-2}\right)$. There are two main potential sources of error in this method. First, the pyrgeometer measures spectrally integrated irradiances, which vary with the atmospheric conditions in a different way to the downwelling radiance measured at a specific angle and wavelength. As an estimate of the magnitude of this error, we have used the root-mean-square scatter of the regression between the sky brightness temperature and the downwelling longwave radiation $(7.9 \mathrm{~K}$, equivalent to an SST error of $0.11 \mathrm{~K}$ ). Second, the radiative transference model assumed a cloudless sky, thus our estimated sky brightness temperatures would be underestimated when cloud was present. The result would be that the estimated skin temperatures would be too high and the magnitude of the cool skin effect underestimated. The observed clouds in SOFIA were 


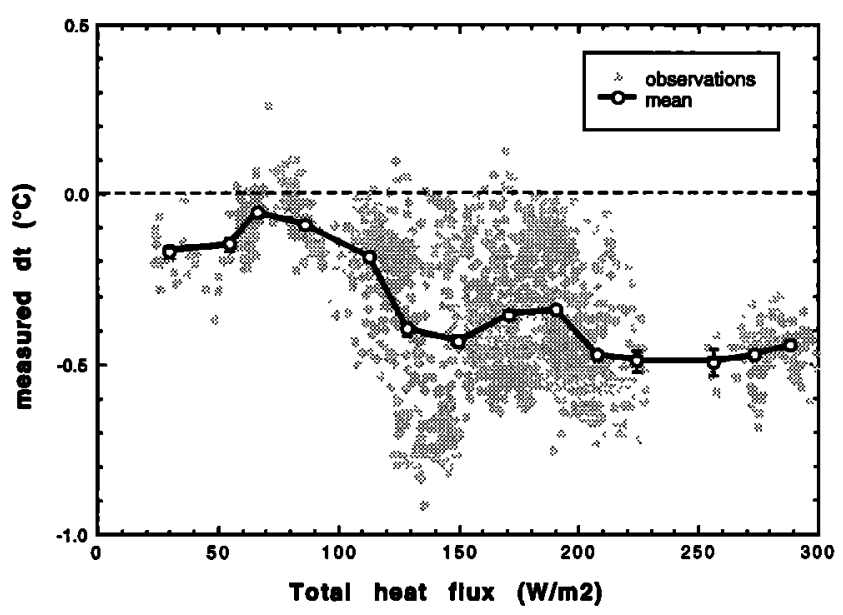

Figure 4. Nighttime values of the measured skin effect, $d t$ (degrees Celsius), plotted against the total heat flux (sensible + latent + net longwave, $\mathrm{W} \mathrm{m}^{-2}$ ). Both individual values and the mean value corresponding to $20 \mathrm{~W} \mathrm{~m}^{-2}$ ranges are shown.

typically cumulus with stratocumulus and two-thirds of the observations gave 6 oktas or greater cloud cover. From the radiosonde ascents the cloud base was generally between 1 and $2 \mathrm{~km}$. Assuming that a cloud emits longwave radiation as if it were a blackbody at the cloud base temperature, the possible bias in the skin temperature measurements can be estimated. It would range up to $0.5 \mathrm{~K}$ (for total cloud cover at $1 \mathrm{~km}$ ) with 0.3 $K$ being a more typical value.

The presence of a bias in the estimates should be detectable by examining nighttime periods when the total heat flux was negligible. In that case it may be assumed that no skin effect should exist (although it should be noted that one of the skin effect formulae to be examined, the statistical model of Schliussel et al. [1990], predicts a value for $d t$ at zero net heat flux of $0.3^{\circ} \mathrm{C}$ during the night). Daytime data are not suitable since the penetration of solar radiation into the water means that zero net heat flux does not then correspond to net heat loss from the surface skin. Unfortunately, to obtain zero net heat flux at night the longwave cooling must be balanced by a total of sensible plus latent heat flux directed into the ocean. Such stable atmospheric conditions tend to be rare over the ocean and did not occur during SOFIA. However, the data can be examined to determine the apparent behavior of the observed skin effect as the total nighttime heat flux becomes small (Figure 4). Somewhat surprisingly, the data do not show obvious evidence of a warm bias. Nor do the comparisons of the skin effect formulae (sections 5 and 6) suggest that the measurements were significantly biased. Indeed, the bias predicted here would have made the comparison with each of the formulae significantly worse. It is suggested that a mean correction for the effect of clouds on the reflected longwave is implicit in the use of the Thomas et al. [1995] correction term. This correction was derived using the same radiative transfer model used here and using data from a stirred water bath which was exposed to the sky. Assuming similar average values for cloud cover and height for the Thomas et al. [1995] and SOFIA data sets (not unlikely over the ocean), then our estimates should not on average be biased.

\subsection{Accuracy of the Radiometer Measurements}

Errors arise from two separate processes, the calibration process (calibration errors) and the sampling process (sampling errors). The former gives rise to errors in the calculated target temperature (SST) which are dependent upon the temperature of the instrument relative to the target, due to the extrapolation made from the calibration temperature range. Each calibration procedure consists of measuring the temperatures of the three blackbodies and also sampling the difference in detected radiation for the cold and hot blackbodies compared to the reference blackbody. Provided the blackbody PRTs are well calibrated, or at least that the Thomas et al. [1995] correction is effective, then errors due to

Table 2. Error Budget for the SIL Radiometer as Used on SOFIA

\begin{tabular}{|c|c|c|c|}
\hline Source & SE & SST Error, ${ }^{\circ} \mathrm{C}$ & Comment \\
\hline \multicolumn{4}{|c|}{ Calibration Errors } \\
\hline $\begin{array}{l}\text { Blackbody } \\
\text { temperature }\end{array}$ & $\begin{array}{l}0.0007^{\circ} \mathrm{C} \\
\quad(\text { each BB })\end{array}$ & 0.003 & (total resulting error) \\
\hline $\begin{array}{l}\text { Detector signal } \\
\text { T }_{\text {CBB }}-\text { SST }=10^{\circ} \mathrm{C}\end{array}$ & $\begin{array}{l}0.5 \text { count } \\
\text { (200 samples) }\end{array}$ & $0.032(0.066)$ & hot (cold) \\
\hline $\begin{array}{l}\text { Detector signal } \\
\mathrm{T}_{\mathrm{CBB}}-\mathrm{SST}=20^{\circ} \mathrm{C}\end{array}$ & $\begin{array}{l}0.5 \text { count } \\
\text { (200 samples) }\end{array}$ & $0.072(0.11)$ & hot (cold) \\
\hline Blackbody emissivity & $\begin{array}{l}\text { reduction by } \\
0.005\end{array}$ & 0.055 & mainly affecting HBB radiation \\
\hline Overall (calibration) & & $0.092(0.143)$ & for $\mathrm{T}_{\mathrm{CBB}}-\mathrm{SST}=10^{\circ} \mathrm{C}\left(20^{\circ} \mathrm{C}\right)$ \\
\hline $\begin{array}{l}\text { Reference blackbody } \\
\text { temperature }\end{array}$ & $0.0007^{\circ} \mathrm{C}$ & $\begin{array}{l}\text { ling Errors } \\
0.001\end{array}$ & 40 samples \\
\hline Detector signal & $\begin{array}{l}0.5 \text { count } \\
\text { (40 samples) }\end{array}$ & $0.016(0.035)$ & for $\mathrm{T}_{\mathrm{CBB}}-\mathrm{SST}=10^{\circ} \mathrm{C}\left(20^{\circ} \mathrm{C}\right)$ \\
\hline $\begin{array}{l}\text { Sky brightness } \\
\text { temperature }\end{array}$ & $7.87 \mathrm{~K}$ & 0.11 & estimated from radiosonde data \\
\hline Target emissivity & $\begin{array}{l}\text { reduction by } \\
0.0021\end{array}$ & 0.095 & \\
\hline Overall (sampling) & & $0.146(0.150)$ & for $\mathrm{T}_{\mathrm{CBB}}-\mathrm{SST}=10^{\circ} \mathrm{C}\left(20^{\circ} \mathrm{C}\right)$ \\
\hline
\end{tabular}

The SST error resulting from the estimated standard errors (SE) for each error source has been estimated. 
the temperature measurement are negligible (less than $0.01^{\circ} \mathrm{C}$ ). Errors in measuring the blackbody radiation have been estimated from the resolution of the measurements and the number of samples taken. If we assume that the inside of the instrument is at a temperature close to that of the cold and reference $\mathrm{BBs}$, only the emissivity of the $\mathrm{HBB}$ will significantly affect the calibration. A change of 0.005 in emissivity causes a change of $0.055^{\circ} \mathrm{C}$ in computed SST. These errors are summarized in Table 2. Taking both calibration and sampling errors into account, the overall error in derived SST is estimated as being $0.17^{\circ} \mathrm{C}$, for a $10^{\circ} \mathrm{C} \mathrm{T}_{\mathrm{CBB}}$ SST difference, and $0.21^{\circ} \mathrm{C}$, for a $20^{\circ} \mathrm{C} \mathrm{T} \mathrm{TBB}_{\mathrm{CB}}$ - SST difference. In each case the largest term in the error budget is likely to be the uncertainty in the sky brightness temperature.

\section{Skin Effect Parameterizations}

\subsection{Saunders [1967] Model}

Saunders [1967], (henceforth "Saunders") used the fact that the heat fluxes must be continuous across the air-sea interface to derive dimensionally the thickness of the oceanic layer where heat is conducted by molecular effects in terms of the wind stress $(\tau)$ and the kinematic viscosity $(v)$ and the density of seawater $\left(\rho_{w}\right)$. The major part of any temperature difference occurs across this conduction layer. This assumes that the heat flux within the ocean varies only slowly between the bulk SST measurement depth and the surface, which assumes that heating due to absorption of solar radiation is "small enough to be ignored", (the validity of this assumption will be discussed in section 6). This flux must then balance the surface sensible plus latent plus net longwave fluxes which is used to determine the heat flux across this thin layer and hence the temperature difference, $d t$, (which, for the purposes of the present paper, is defined to be negative when the ocean surface skin is colder than to the subsurface water):

$$
-d t=\frac{\lambda_{s} Q v}{K\left(\tau / \rho_{w}\right)^{1 / 2}}
$$

where $Q$ is the sum of $H_{s}$ (the sensible heat flux), $H_{l}$ (the latent heat flux), and $l w_{n e t}$ (the effective back radiation); $\lambda_{s}$ is a numerical factor, containing amongst other effects the factor that represents the frictional component of the wind speed; $K$ is the thermal conductivity of seawater. Saunders had little data to test his equation but suggested that $\lambda_{s}$ was between 5 and 10 and probably about 7 . Using data obtained during the Global Atlantic Tropical Experiment, Grassl [1976] found that $\lambda_{s}$ increased from about 2 in light winds to about 5.5 for winds above $6 \mathrm{~m} \mathrm{~s}^{-1}$. However, while noting that $\lambda_{s}$ must decrease at low wind speeds, Paulson and Simpson [1981] found $\lambda_{s}$ to be constant over the wind speed range 3 to $11 \mathrm{~m} \mathrm{~s}^{-1}$, with the value $6.5 \pm 0.6$.

In very light winds (less than $2 \mathrm{~m} \mathrm{~s}^{-1}$ ) Saunders suggested a different formula. At large Richardson numbers free convection occurs and $d t$ has the form

$$
-d t=(Q / \beta)^{3 / 4}
$$

where $Q$ is dominated by the net longwave, and $\beta$ is given by $0.2 K(g \alpha / \kappa v)^{1 / 3}$ ( $K$ is the coefficient of thermal diffusion, $g$ is the acceleration due to gravity) and is tabulated, by Saunders, as a function of bulk SST. At a SST of $20^{\circ} \mathrm{C}, \beta$ is $300 \mathrm{~W} \mathrm{~m}{ }^{-2}{ }^{\circ} \mathrm{C}^{-4 / 3}$. We have applied these data both to nighttime and daytime data. The results will be shown separately since the formula is not expected to be valid when solar heating is significant.

\subsection{Hasse [1971] Model}

Hasse [1971] (henceforth "Hasse") developed a physical model which he compared with estimates of $d t$ from data recorded on a floating buoy. The model was derived by making assumptions about the effective thermal diffusivity in the water. In the surface skin layer the thermal diffusivity was assumed to be the same as the molecular diffusivity, and away from the skin layer it was represented by an eddy diffusivity. Between these two regimes the profiles were assumed continuous. This gave $d t$ proportional to the ratio of the heat flux to the wind speed although the proportionality is not strict; $d t$ was then given by

$$
-d t=c_{1} \frac{Q}{u}+c_{2} \frac{s w_{i n}}{u}
$$

where $u$ is the wind speed, $s w_{\text {in }}$ the incoming solar radiation and $c_{1}$ and $c_{2}$ are coefficients which have an approximately logarithmic dependence on the depth of the bulk SST measurement and with $c_{1}$ about 10 times larger than $c_{2}$. Given that most of the data used in this paper were collected from estimated depths between $0.1 \mathrm{~m}$ and $1 \mathrm{~m}$, we have chosen to use the values suggested by Hasse for $0.25 \mathrm{~m}$. The variation of the coefficients for other depths is illustrated in Table 3. Hasse stated that the model was not valid at low wind speeds (less than $2 \mathrm{~m} \mathrm{~s}^{-1}$ ) or at high wind speeds when there are breaking waves.

\subsection{Schlüssel et al. [1990] Model}

Schliussel et al. [1990] (henceforth "Schlüssel") measured radiative SSTs at about $30^{\circ} \mathrm{N}, 20^{\circ} \mathrm{W}$ in the Northeast Atlantic during October and November. Bulk SST was measured at four levels, radiation measurements of the downward shortwave and longwave and mean meteorological measurements were obtained to enable the computation of the sensible and latent heat fluxes.

Either the fluxes, or the fluxes divided by the wind speed, were statistically fitted to the data obtained separately for nighttime and daytime observations. The best fits were, during the night,

Table 3. Values of the Coefficients, $c_{1}$ and $c_{2}$, in the Hasse Formulae

\begin{tabular}{cccll}
\hline Depth, $\mathrm{m}$ & 0.01 & 0.10 & 0.25 & 1 \\
\hline $\mathrm{c}_{1}$ & 8.2 & 9.1 & 9.4 & 9.9 \\
$\mathrm{c}_{2}$ & 0.9 & 1.4 & 1.61 & 1.90 \\
\hline
\end{tabular}

The values for 0.01 and $0.1 \mathrm{~m}$ have been extrapolated using a logarithmic fit. 


$$
\begin{aligned}
-d t= & -0.285+0.0115 u\left(T_{s}-T_{a}\right)+37.255\left(q_{s}-q_{a}\right) \\
& +0.00212 l w_{n e t}
\end{aligned}
$$

and during the day,

$$
\begin{aligned}
-d t= & -0.415+\frac{0.00337 s w_{\text {net }}}{u}+48.043\left(q_{s}-q_{a}\right) \\
& +0.00355 l w_{\text {net }}
\end{aligned}
$$

where $T_{s}$ and $T_{a}$ are the bulk SST and the air temperature in ${ }^{\circ} \mathrm{C}$, $q_{s}$ and $q_{a}$ are the mixing ratios for the air at the sea surface and at $20 \mathrm{~m}$ height in $\mathrm{kg} \mathrm{kg}^{-1}$. Coefficients have the dimensions needed to give a dimensionally consistent equation. Being a statistical model optimized for a particular area and season, the applicability of this model to other conditions needs to be established.

\subsection{Soloviev and Schlüssel [1994] Model}

Soloviev and Schlüssel [1994] (henceforth Soloviev) developed a "surface renewal" model. It was assumed that $d t$ is a function of the friction velocity $\left(u_{m}\right)$, the sum of the sensible, latent and net longwave fluxes, the thermal expansion of water $(\alpha)$, the acceleration due to gravity $(g)$, and the coefficients of thermal diffusion $(\kappa)$ and molecular viscosity $(v)$. These parameters will take into account the effects of thermally driven convection, wind-induced turbulence and gravity waves on the surface layer. Dimensional analysis gives $d t$ to be a function of the following nondimensional parameters:

Surface Richardson number, $\mathrm{Rf}_{0} \quad-\alpha g\left(\frac{Q}{c_{p} \rho}\right) \frac{\mathrm{v}}{u_{*}^{4}}$

Prandtl number, $\operatorname{Pr} \quad$ v/א

Keulegan number, $\mathrm{Ke} \quad u_{*}^{3} / g v$

These are combined with consideration for the renewal of fluid in the molecular sublayer and the physics of the motions to give

$$
\begin{aligned}
-d t= & \frac{Q}{c_{p} \rho_{w} u_{*}} \Lambda_{0} \operatorname{Pr}^{1 / 2}\left(1+R f_{0} / R f_{c r}\right)^{-1 / 4} \\
& \times\left(1+K e / K e_{c r}\right)^{1 / 2}
\end{aligned}
$$

where $\Lambda_{O}$ is related to the surface renewal rate and is taken as a constant value of 13.3. $R f_{c r}$, and $K e_{c r}$ are critical values of the Richardson and Keulegan numbers and are determined from experimental data.
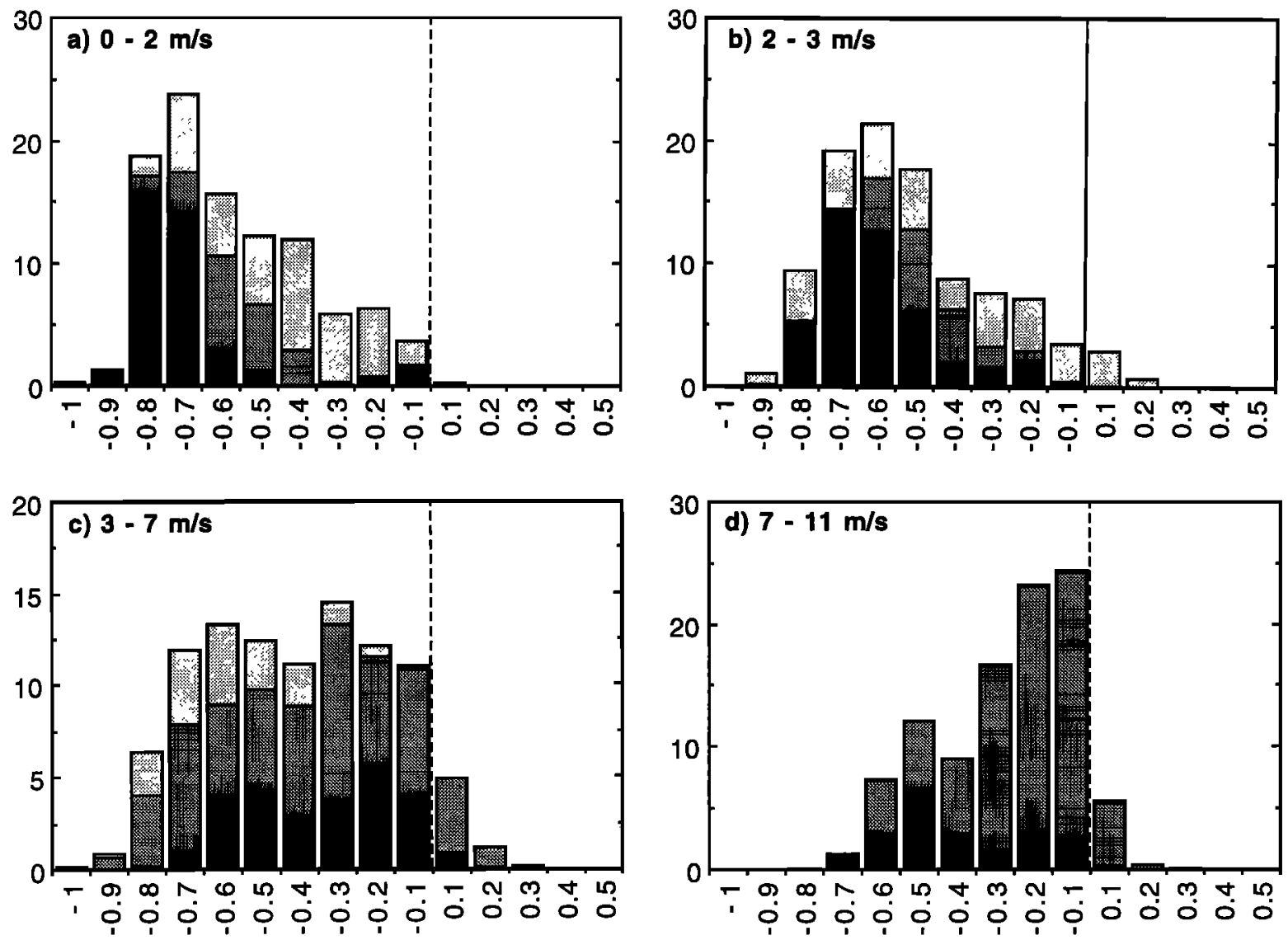

Figure 5. Histograms of the percentage of the observations (y axis) contained in $0.1^{\circ} \mathrm{C}$ intervals of the measured skin effect, $d t$, ( $x$ axis), for different wind speed ranges: (a) $0-2 \mathrm{~m} \mathrm{~s}^{-1}$ (303 observations); (b) $2-3 \mathrm{~m} \mathrm{~s}^{-1}$ (489 observations); (c) $3-7 \mathrm{~m} \mathrm{~s}^{-1}$ (3839 observations); (d) $7-11 \mathrm{~m} \mathrm{~s}^{-1}$ (1006 observations, 71 above $9 \mathrm{~m} \mathrm{~s}^{-1}$ ). The shading represents the percentage of observations in each wind speed range at night (insolation $<10 \mathrm{~W} \mathrm{~m}^{-2}$, dark shading); under medium insolation (10 to $800 \mathrm{~W} \mathrm{~m}^{-2}$, medium shading); and under high insolation (greater than $800 \mathrm{~W} \mathrm{~m}^{-2}$, light shading). 
The model is not thought to be a complete description of processes at high wind speeds when bubbles and spray may play an important role. Although the parameterization does not include the effects of solar radiation, the authors state that it is applicable during the daytime except during conditions of strong insolation near local noon time. This is because, like Saunders, they assume the insolation is a volume source of heat and does not affect the molecular sublayer preferentially. The authors do not, however, test the parameterization during daytime. In this paper we will apply this parameterization for all values of insolation.

\section{Results}

\subsection{Variation of the Skin Effect With Wind Speed}

The four parameterizations described in section 4 have various limitations on the wind speed range for which they are valid. For example, while Saunders presents a specific model for wind speeds below $2 \mathrm{~m} \mathrm{~s}^{-1}$, the Hasse model is not expected to be valid at low wind speeds, and neither the Hasse nor Soloviev models are claimed to be valid at higher wind speeds when waves are breaking. The distribution of observed skin effect values, $d t$, for different wind speed ranges is illustrated in Figure 5. For each wind speed range the percentage contribution is shown for "nighttime" data (isolation $<10 \mathrm{~W}$ $\mathrm{m}^{-2}$ ), daytime data under moderate insolation $\left(\leq 800 \mathrm{~W} \mathrm{~m}^{-2}\right)$, and high insolation $\left(>800 \mathrm{~W} \mathrm{~m}^{-2}\right.$ ). Significant variations occurred in these $d t$ distributions. For example, at low wind speeds $\left(<2 \mathrm{~m} \mathrm{~s}^{-1}\right)$ the most likely $d t$ value was about $-0.7^{\circ} \mathrm{C}$, and small skin temperature deviations $\left(-0.3^{\circ} \mathrm{C}<d t<0.1\right)$ were mostly associated with high insolation values. In contrast, at high wind speeds $\left(>7 \mathrm{~m} \mathrm{~s}^{-1}\right.$ ), the most likely $d t$ value was $-0.1^{\circ} \mathrm{C}$. The performance of the different parameterizations will therefore be considered separately for different wind speed ranges.

\subsection{Low Wind Speed Parameterization}

\subsubsection{Comparison of the parameterizations at low} wind speed. Ignoring cases of high insolation, the observations (Figure 5a) showed a distribution peak for $d t$ at about $-0.7^{\circ} \mathrm{C}$, the range being narrowest during the night. In contrast, the three parameterizations claimed to be valid below $2 \mathrm{~m} \mathrm{~s}^{-1}$ wind speed each predicted a narrow distribution of values for $d t$, with peaks at $-0.4^{\circ} \mathrm{C}$ (Saunders), $-0.1^{\circ} \mathrm{C}$ (Schlüssel), or $-0.3^{\circ} \mathrm{C}$ (Soloviev); see Figure 6. None of these parameterizations correctly predicted the observed variability; the Saunders values were closest to the observed magnitude of $d t$.
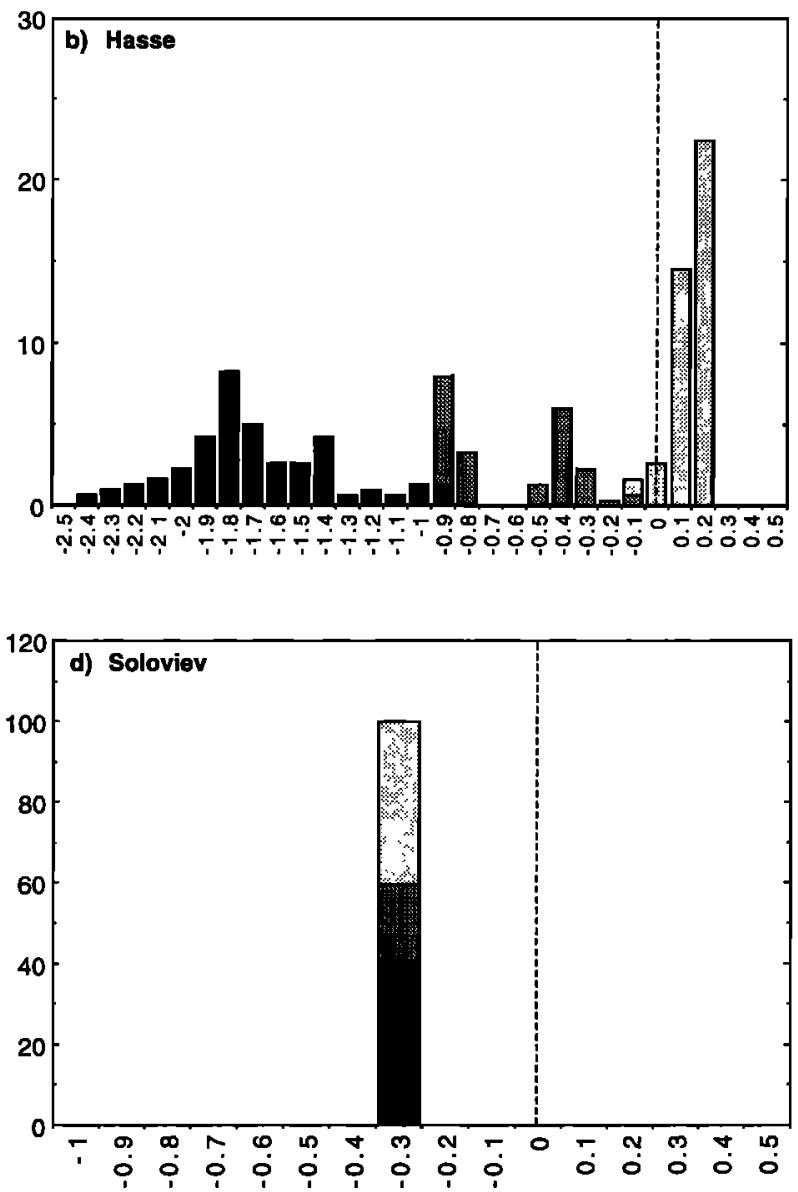

Figure 6. Histograms of the percentage of the predicted skin effect (y axis) contained in $0.1^{\circ} \mathrm{C}$ intervals ( $x$ axis), for low wind speeds $\left(<2 \mathrm{~m} \mathrm{~s}^{-1}\right.$ ) for different formulae: (a) Saunders (free convection model), (b) Hasse, (c) Schlüssel, and (d) Soloviev. The shading indicates the number of observations under different insolation conditions (see Figure 5). Note that the Hasse values extend over a greater range of $d t$ values. 
The apparent effect of high solar radiation on the skin effect seen in Figure 5a suggested that the Hasse formula, though not claimed to be valid at low wind speeds, might model the observations. However, while the results (Figure 6b) showed a small or positive skin effect at high solar radiation $\left(d t>0^{\circ} \mathrm{C}\right)$, much too great a skin effect (between -1 and $-2.5^{\circ} \mathrm{C}$ ) was predicted at night. To examine the effect of high insolation at low wind speeds further, Figure 7 shows scatterplots for daytime data only, for the Saunders and Hasse parameterizations. For this plot, all data for winds under $3 \mathrm{~m} \mathrm{~s}^{-1}$ have been included with the different Saunders formulae (equations (11) and (12)) used as appropriate. For the highinsolation cases the Saunders formulae predicted $d t \approx-0.4^{\circ} \mathrm{C}$ for winds below $2 \mathrm{~m} \mathrm{~s}^{-1}$, and about $-0.8^{\circ} \mathrm{C}$ for winds between 2 $\mathrm{m} \mathrm{s}^{-1}$ and $3 \mathrm{~m} \mathrm{~s}^{-1}$. In contrast the Hasse formula predicted that all high-insolation $d t$ values should lie in the range $-0.1^{\circ} \mathrm{C}<d t$ $<0.3^{\circ} \mathrm{C}$; a prediction which only fits a fraction of the data. In both cases it appeared that, if the data at high solar radiation were omitted, the agreement between the measurements and the models was improved. The following section presents a case study illustrating that, if at low wind speeds and strong solar heating the water column becomes stratified, the measured $d t$ values may not represent the temperature drop across the skin layer.

5.2.2. High-insolation case study: day 161. June 10 (day 161) was the only day during SOFIA on which a marked decrease of the skin effect with solar radiation was observed. On this day, lack of cloud cover resulted in strong solar heating (Figure 8a). Whereas the cooling due to the net longwave, sensible and latent heat fluxes was between 100 and $200 \mathrm{~W} \mathrm{~m}^{-2}$, the shortwave heating was greater than $800 \mathrm{~W} \mathrm{~m}^{-2}$ over a significant fraction of the day. Wind speeds (Figure $8 \mathrm{~b}$ ) were low, being below $2 \mathrm{~m} \mathrm{~s}^{-1}$ between about 1130 and 1400 hours; this period is marked by vertical lines in Figure 8 .

A time series of thermistor and bucket measured SST is shown in Figure 8c. The observed SST increased during the period of solar heating and low wind speeds. Although the total heat flux was directed into the ocean until about 1900 hours, the observed SST decreased after about 1630 hours, presumably because of the increased wind mixing. Compared to the trailed thermistor, the bucket SST was cooler except during and directly following the period of low wind speeds. At about 1300 hours the bucket SST was significantly warmer than the thermistor values; the two temperatures then became similar as the wind mixing increased. These data would be consistent with solar radiation heating the upper meters of the ocean in the absence of wind mixing, provided that the bucket temperatures were obtained from a shallower depth than the thermistor. This is possible since, although the thermistor was usually at very shallow depths when the ship was steaming, during this period the ship was drifting slowly. This would have allowed the thermistor to sink in the water to depths of about 1 to $3 \mathrm{~m}$.

The measured (radiometer - thermistor) skin effect, $d t$, and the estimate from the Hasse formula are shown in Figure 8d. The $d t$ predicted by Hasse rises simultaneously with the solar radiation increase (Figure 8a); the measured $d t$ started to rise only when the wind speed drops below $2 \mathrm{~m} \mathrm{~s}^{-1}$. This behavior can be explained, not by the solar radiation decreasing the skin effect, but by the solar radiation warming the water column with a decrease in warming with depth, thus masking the skin effect. This is illustrated in Figure 9. At higher wind speeds the first few meters of the water column are well mixed
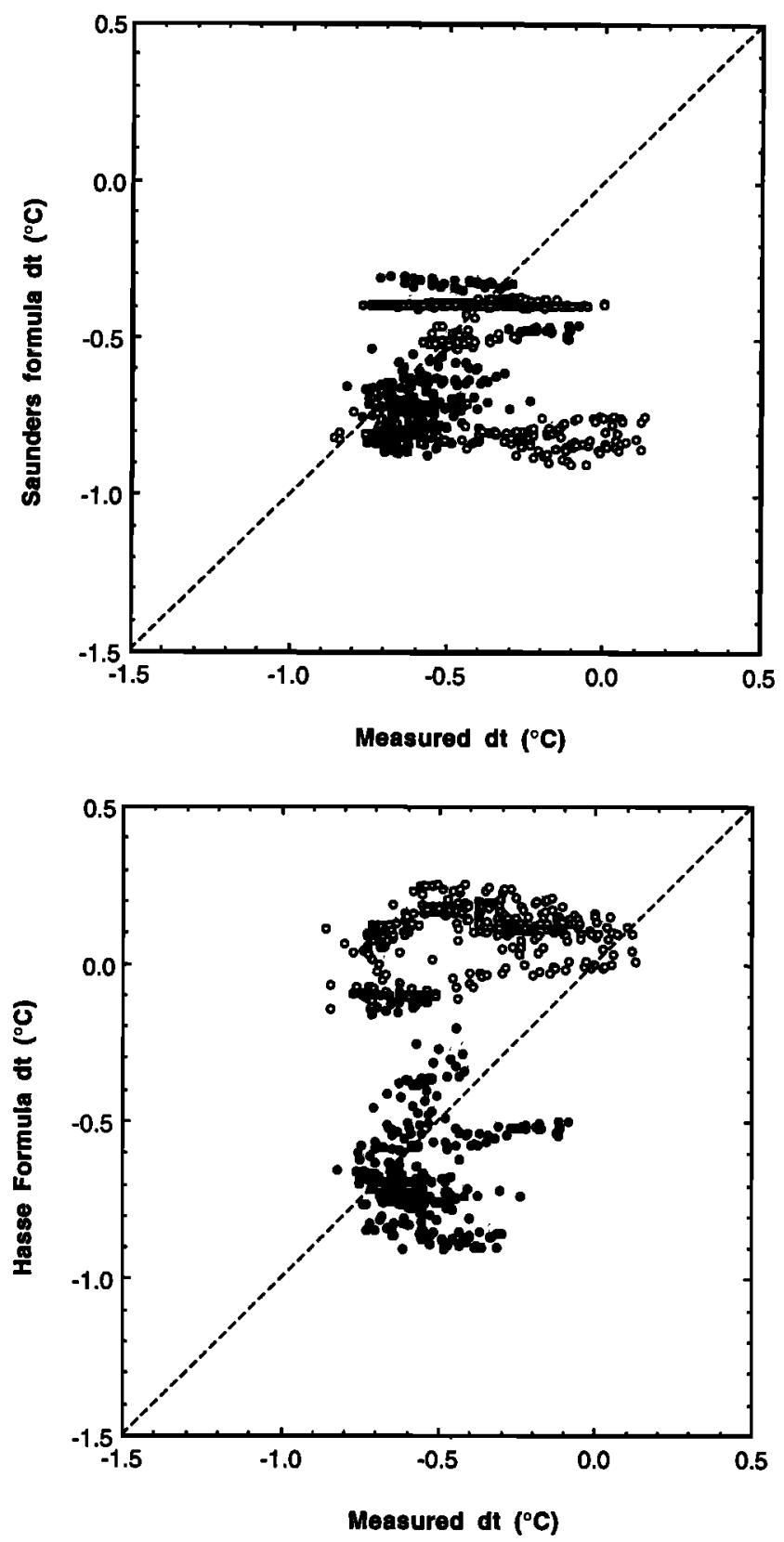

Figure 7. Comparison of predicted skin effect, degrees Celsius, with measured skin effect. Values corresponding to high insolation ( $>800 \mathrm{~W} \mathrm{~m}^{-2}$ ) are shown by open symbols: (a) Saunders formulae and (b) Hasse formula.

and the effects of solar radiation would not be noticeable. In very light winds the near surface water is preferentially warmed compared to the water at the bulk SST measurement depth and the magnitude of the apparent $d t$ is reduced, although the true $d t$ remains the same. The presence of a near surface thermocline of this sort has been studied, for example, by Price et al. [1987]; diurnal temperature changes in the near surface water of a few degrees Celsius have been observed.

The rate of the apparent decrease in skin effect depends on the difference between the radiative heating just below the surface and the radiative heating at the bulk SST measurement depth. Paulson and Simpson [1977] developed a simple model which gives the irradiance, $I$, at a depth, $l$, as a function of the 


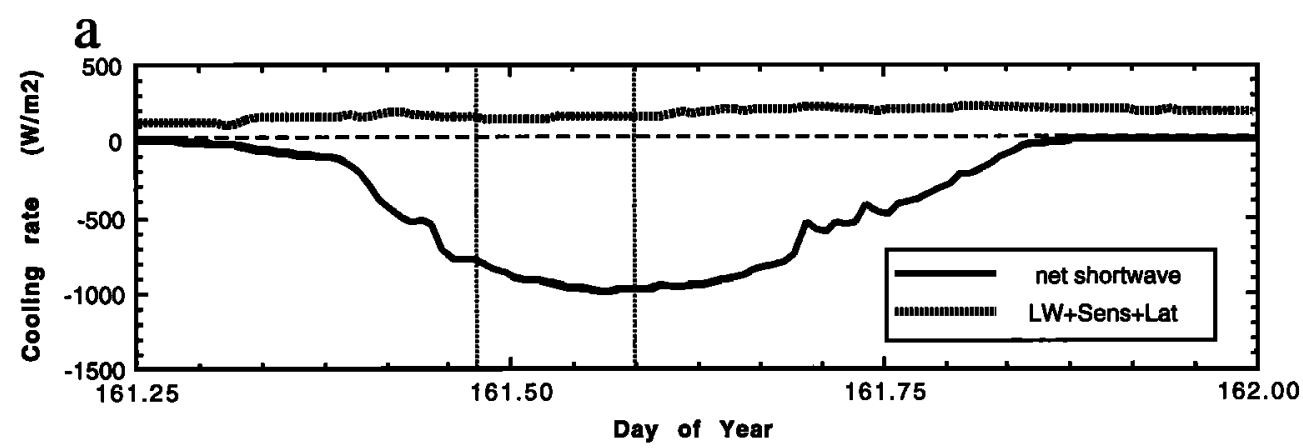

b

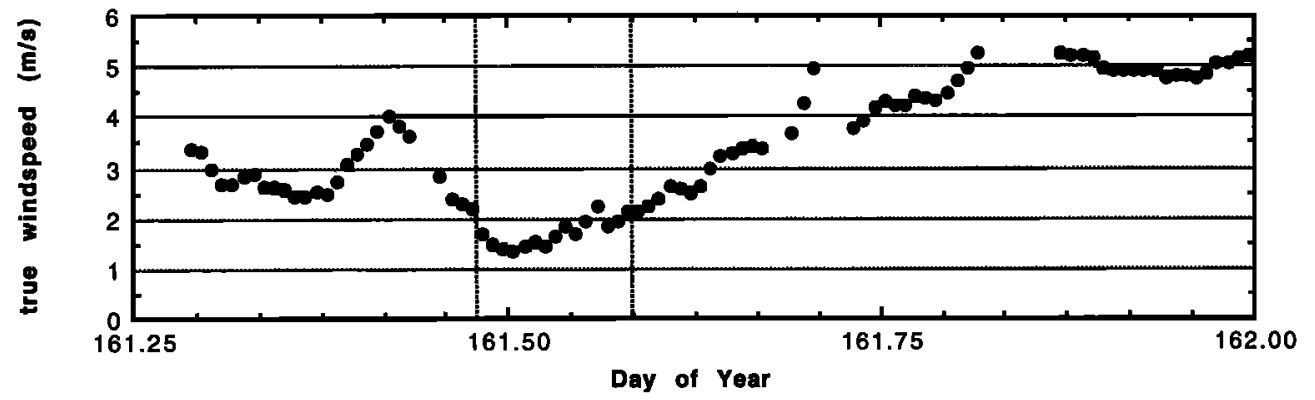

C

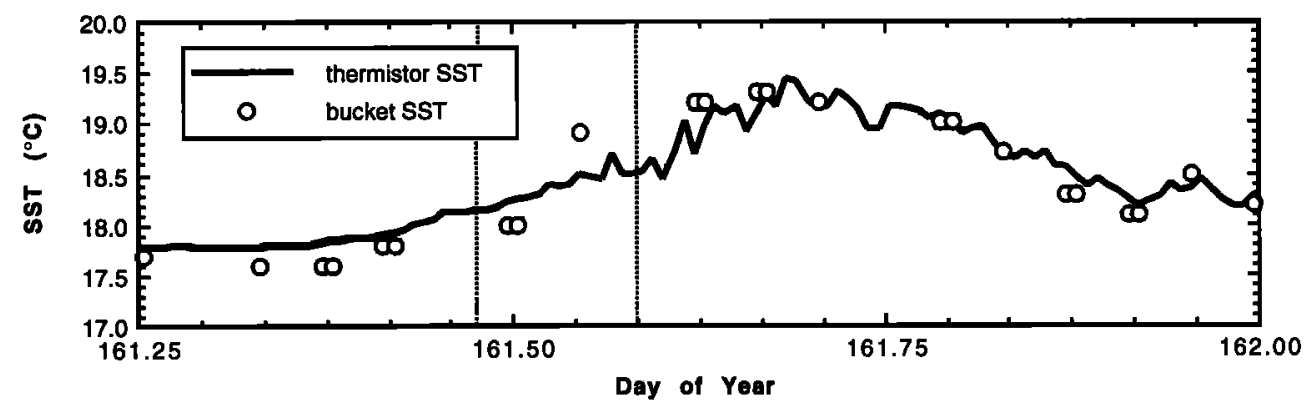

d

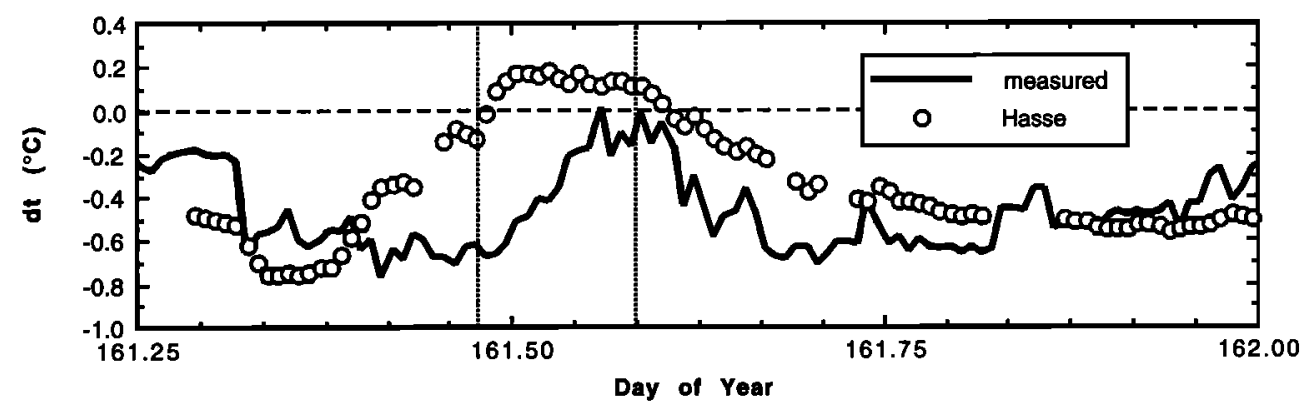

Figure 8. Time series of observations for day 161; on each plot the period of winds less than $2 \mathrm{~m} \mathrm{~s}^{-1}$ is marked by vertical lines. (a) Net shortwave radiation (solid line) and surface cooling (net longwave + sensible + latent heat fluxes); (b) true wind speed $\left(\mathrm{m} \mathrm{s}^{-1}\right.$ ); (c) sea surface temperature from bucket and thermistor; (d) measured skin effect, $d t{ }^{\circ} \mathrm{C}$, and values predicted by the Hasse formula.

surface irradiance and two exponential functions which represent the enhanced absorption in the infrared at the surface and the deeper penetration at other wavelengths. Using this model for the radiative absorption, and assuming that in light winds the heat loss due to surface cooling is distributed through the top meter of the ocean, the rate at which the apparent skin effect would decrease was calculated for different assumed thermistor depths. Thus the rate of change with time $T$ was

$$
\frac{\partial(d t)}{\partial T}=\frac{\left.(\partial I / \partial z)\right|_{z_{1}}-\left.(\partial I / \partial z)\right|_{z_{2}}}{c_{p} p}
$$

with $z_{1}$, taken to be $1 \mathrm{~cm}$, a depth of $2 \mathrm{~m}$ for $z_{2}$ gave the observed heating rate (Figure 10). 


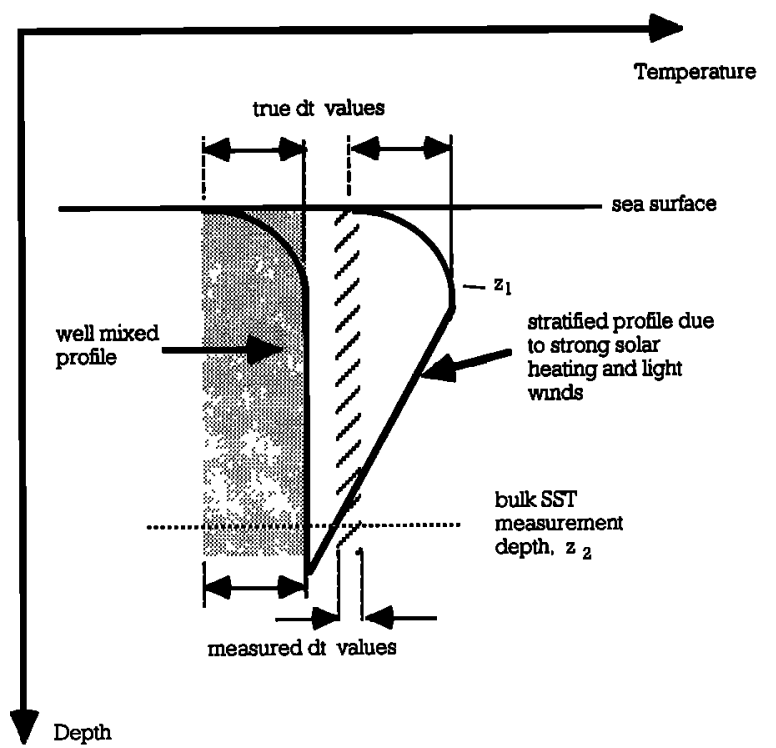

Figure 9. Schematic showing the suggested mechanism for apparent solar warming of the thermal skin layer. The dotted area on the left indicates the magnitude of the well-mixed value for $d t$ which is also the true value. The hatched area on the right indicates the apparent value that would be measured for $d t$ when the water is thermally stratified. Variable $z_{1}$ indicates the depth at which a bulk SST measurement would indicate the true cool skin value; $z_{2}$ indicates that at which a warm skin would be observed.

This example illustrates that to predict the observed value of $d t$ at low wind speeds and high solar radiation, knowledge of the heating and mixing history of the water column is required, that is how long the upper layer has been heated in the absence of mixing. Thus, if the water column is stratified, no skin effect formulae can be used to estimate the difference between the skin temperature and a bulk SST measurement in terms of the observed variables at the time of estimation.

\subsection{Moderate to High Winds}

Figures 11a-11d show scatterplots of the four parameterizations against the measured $d t$ (radiometer trailing thermistor SST) for wind speeds between $3 \mathrm{~m} \mathrm{~s}^{-1}$ and $7 \mathrm{~m} \mathrm{~s}^{-1}$. The Saunders estimate (Figure 11a) gave the best approximation to the measured data. The greatest scatter was shown by the Hasse and by the Schlüssel parameterizations (Figures $11 \mathrm{~b}$ and 11c). These parameterizations both contain a solar radiation term of similar magnitude, which was not observed in the data (see section 6). The Soloviev estimate (Figure 11d) gave the gradient most different from unity and a very limited range of predictions.

Very little data were available at higher wind speeds (above $7 \mathrm{~m} \mathrm{~s}^{-1}$ ). However, the distribution of the observed $d t$ (Figure 5d) peaks just below zero skin effect. No skin effect would be expected if the sea surface were continually broken by the action of the wind. The progression that can be seen in the modal value of $d t$ as the wind speed increases (from $-0.7^{\circ} \mathrm{C}$ at low wind speeds, -0.3 at moderate wind speeds to -0.1 at higher wind speeds) suggests that the sea surface layer is being destroyed more often as the wind increases, leading to a smaller observed skin effect on average. The range of values of observed skin effect $(-0.9$ to 0.1$)$ is about the same for each wind speed range, but the shape of the distributions varies dramatically with wind speed.

\section{Discussion: Comparison of the Parameterizations}

The mean values of skin effect for the SOFIA data set are shown in Figure 12, averaged in incremental ranges of shortwave insolation, surface cooling, and wind speeds. The apparent variation of $d t$ with shortwave insolation (Figure 12a) showed little variation in the magnitude of $d t$ with increasing insolation up to about $-600 \mathrm{~W} \mathrm{~m}^{-2}$ with an increase under sunny conditions. Although this behavior is counter to what might have been expected; it was well reproduced by the Saunders formula which does not include a solar radiation term. In contrast, the Hasse formulae predicted a significant decrease with increasing insolation which was not observed. This indicates that the observed effect was due to a correlation of the observed solar radiation with the wind speed or the other fluxes, rather than an influence of insolation on the skin effect. This is plausible, since sunny conditions might correlate with dry, cold air and large surface cooling. Neither the Schlüssel nor Soloviev models performed as well as the Saunders formula in reproducing these observed $d t$ values.

It is relevant to consider why the shortwave radiation should not make a major contribution to the surface skin effect. Following, for example, Saunders, it can be assumed that the solar energy penetrating below the skin layer of the ocean is mixed away. The relevant value is then the amount of solar radiation absorbed in the skin layer. Paulson and Simpson [1977] describe a simple model to estimate the amount of radiation absorbed as a function of depth. The amount of solar radiation absorbed in skin layers of differing thicknesses was calculated with this model. In an alternative calculation the solar absorption in water as a function of wavelength [Aksenov and Khundzhua, 1986] was combined with a Planck function for the solar temperature. The solar absorption in the atmosphere was estimated from HendersonSellers and Robinson [1986] and energy at the strongly absorbing wavelengths removed from the Planck spectrum.

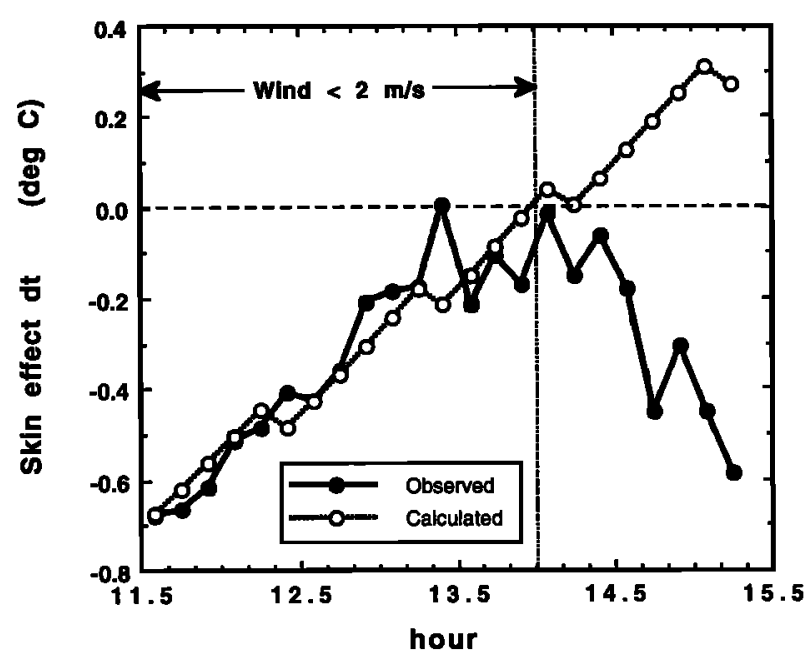

Figure 10. Time series of the observed and calculated values for the apparent skin effect, $d t$ (degrees Celsius), during 4 hours on day 161 . The period during which the wind speed was less than $2 \mathrm{~m} \mathrm{~s}^{-1}$ is indicated. 

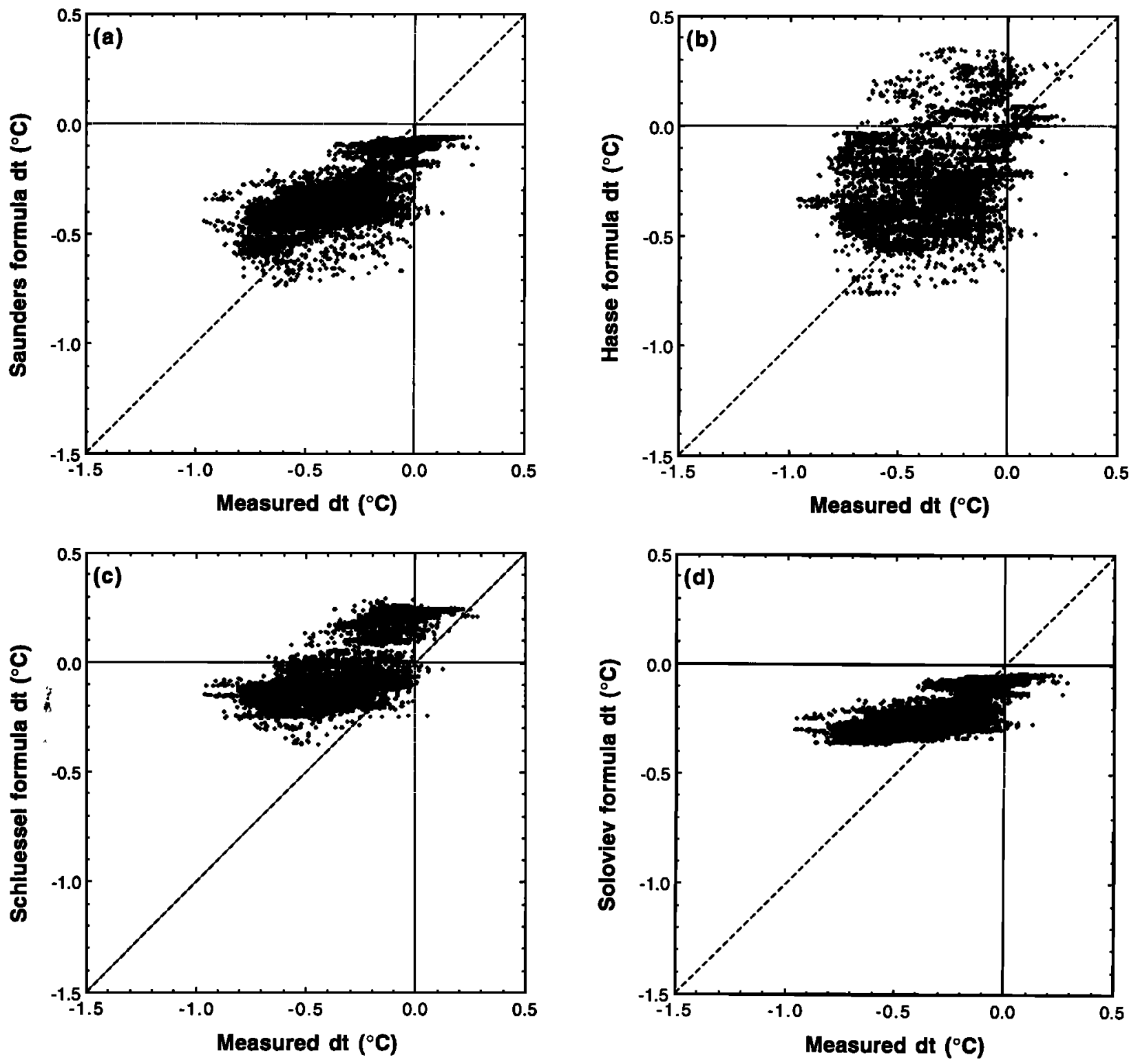

Figure 11. Comparison of predicted skin effect, degrees Celsius, with measured skin effect during periods when the wind speed was between 3 and $7 \mathrm{~m} \mathrm{~s}^{-1}$ : (a) Saunders, (b) Hasse, (c) Schlüssel, and (d) Soloviev. The dashed line indicates perfect agreement.

The resulting spectrum was combined with the absorption coefficient values from Aksenov and Khundzhua [1986] which enabled the energy absorbed in skin layers of varying thickness to be estimated. The two models agreed well for skin thicknesses below $0.1 \mathrm{~mm}$, giving percentage absorptions of about $4 \%$ at $0.1 \mathrm{~mm}$, and less than $2 \%$ at 10 $\mu \mathrm{m}$. For a thicker skin layer the Paulson and Simpson [1981] percentage absorption became larger and predicted about $12 \%$ absorption in $1 \mathrm{~mm}$ compared with $8 \%$ for the Aksenov and Khundzhua [1986] model. The figures for $10 \mathrm{~mm}$ are $15 \%$ and $24 \%$, respectively. The important factor is therefore the thickness assumed for the skin layer. If, following Saunders, the thickness of the skin layer is assumed to be about $0.3 \mathrm{~mm}$, this implies 5\% absorption from the more detailed Aksenov and Khundzhua [1986] model. However, Robinson et al. [1984] suggest a skin thickness of only $0.1 \mathrm{~mm}$. Even for peak solar heating of say $1000 \mathrm{~W} \mathrm{~m}^{-2}$ the implied change in the surface skin temperature would only be about $0.1^{\circ} \mathrm{C}$. Indeed Khundzhua and Aksenov [1986, p.10] conclude "that the ocean cold film may be considered transparent for penetrating solar radiation in most cases."

Considering next the apparent variation with the net surface cooling (Figure 12b), all the parameterizations predicted the observed increase in magnitude of $d t$ with increasing cooling. The Schlüssel formulae best predicted the rate of decrease but the $d t$ values were biased warm. The Hasse model showed a more erratic variation with net cooling, as would be expected from its poor parameterization of the effects of solar radiation in this data set. The Saunders formula performed better than the Soloviev model.

Most of the parameterizations failed to predict the apparent variation of $d t$ with wind speed (Figure 12c). The Saunders 

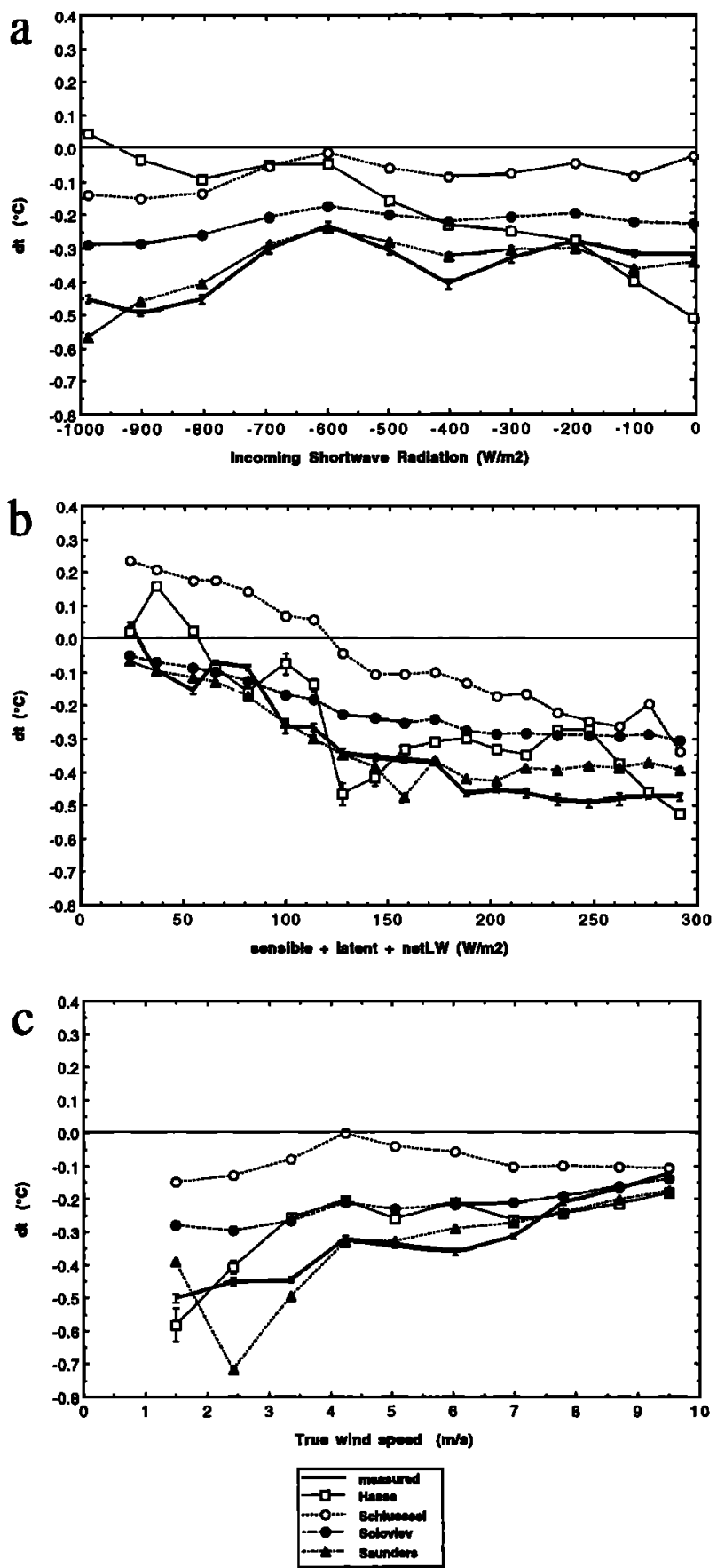

Figure 12. Measured and predicted of $d t$ averaged in ranges of (a) insolation $\left(\mathrm{W} \mathrm{m}^{-2}\right)$; (b) surface cooling (sensible heat + latent heat + net longwave, $\left.\mathrm{W} \mathrm{m}^{-2}\right)$; (c) wind speed $\left(\mathrm{m} \mathrm{s}^{-1}\right)$.

formulae performed best, bracketing the observed behavior at low wind speeds and predicting the correct values up to about 8 $\mathrm{m} \mathrm{s}^{-1}$. The values of $d t$ at higher wind speed are slightly overestimated. Where the formulae required an estimate of the stress or friction velocity in the water, it has been calculated from that in air using the ratio of the densities. This assumes that all the wind stress is available to cause mixing within the ocean and ignores, for example, advection of momentum in the surface wave field. For most of the formulae the variation of the predicted skin effect with wind speed was too low and any reduction in the estimated friction velocity would have made the behavior of the formulae even less realistic.

The overall mean scatter and bias of the different parameterizations is shown in Figures 13a and 13b for wind speeds below and above $3 \mathrm{~m} \mathrm{~s}^{-1}$, respectively. At low wind speeds the Saunders formulae clearly had the least bias and similar scatter to the Schlüssel and Soloviev models. At higher wind speeds the bias and scatter of the Saunders model was least; although the performance of the Soloviev model appeared similar, but with an increased bias. Taking into account the uncertainty in the radiometer calibration, either could be correct. However, the Saunders model could be tuned to agree with a different radiometer bias by adjusting $\lambda_{s}$.

It is instructive to calculate the values of $\lambda_{s}$ in the Saunders formula implied by the SOFIA values of $d t$. The distribution of the calculated $\lambda_{s}$ values is shown in Figure 14 together with the mean $\lambda_{s}$ value. As recognized by Soloviev and Schluissel [1994], the Soloviev model can be used to evaluate, from physical arguments, values for $\lambda_{s}$ for use in the Saunders model (compare (10) and (15)); their values for the SOFIA data are
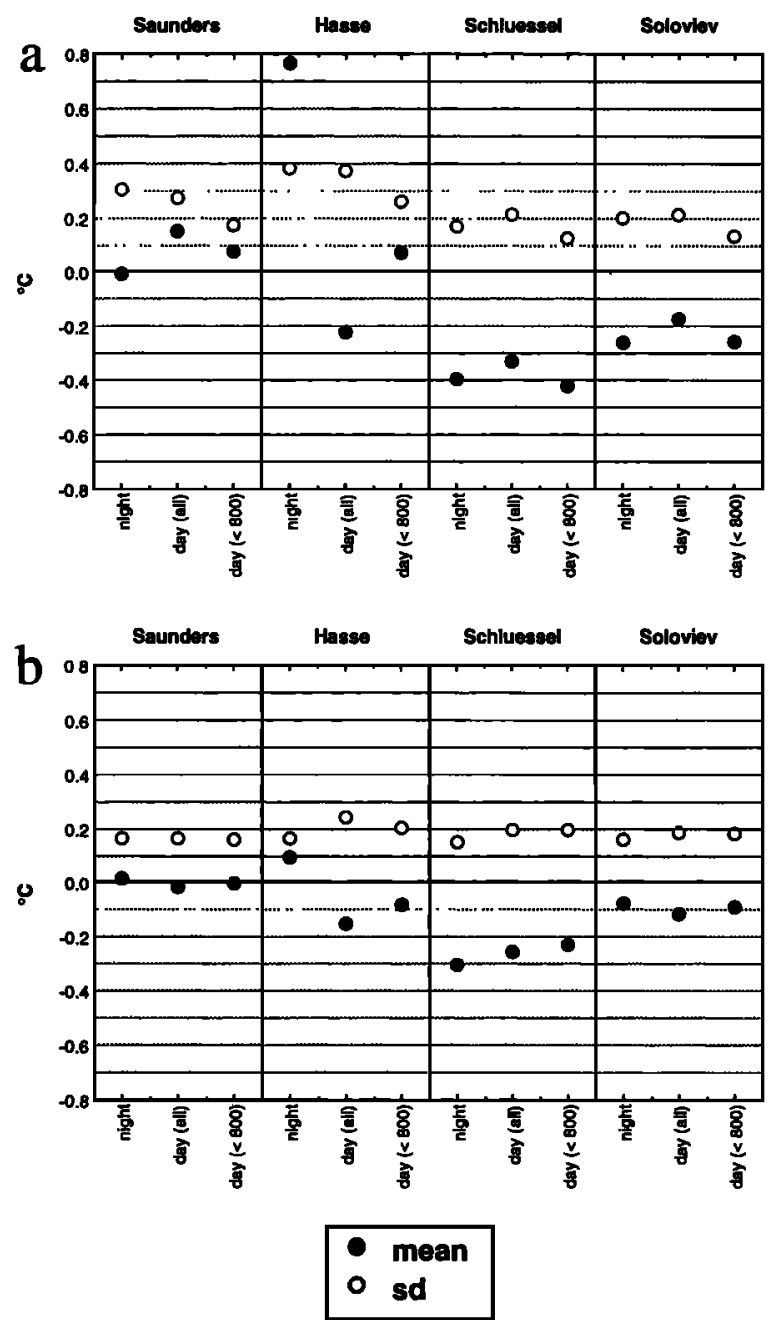

Figure 13. Summary of the performance of the different skin effect formula. For each formula, the mean and standard deviation of the difference between the measured and predicted $d t$ values is shown separately for nighttime data, all daytime data, and daytime data excluding cases of high solar insolation $\left(>800 \mathrm{~W} \mathrm{~m}^{-2}\right)$. (a) Wind speeds less than $3 \mathrm{~m} \mathrm{~s}^{-1}$. (b) Wind speeds greater than $3 \mathrm{~m} \mathrm{~s}^{-1}$. 

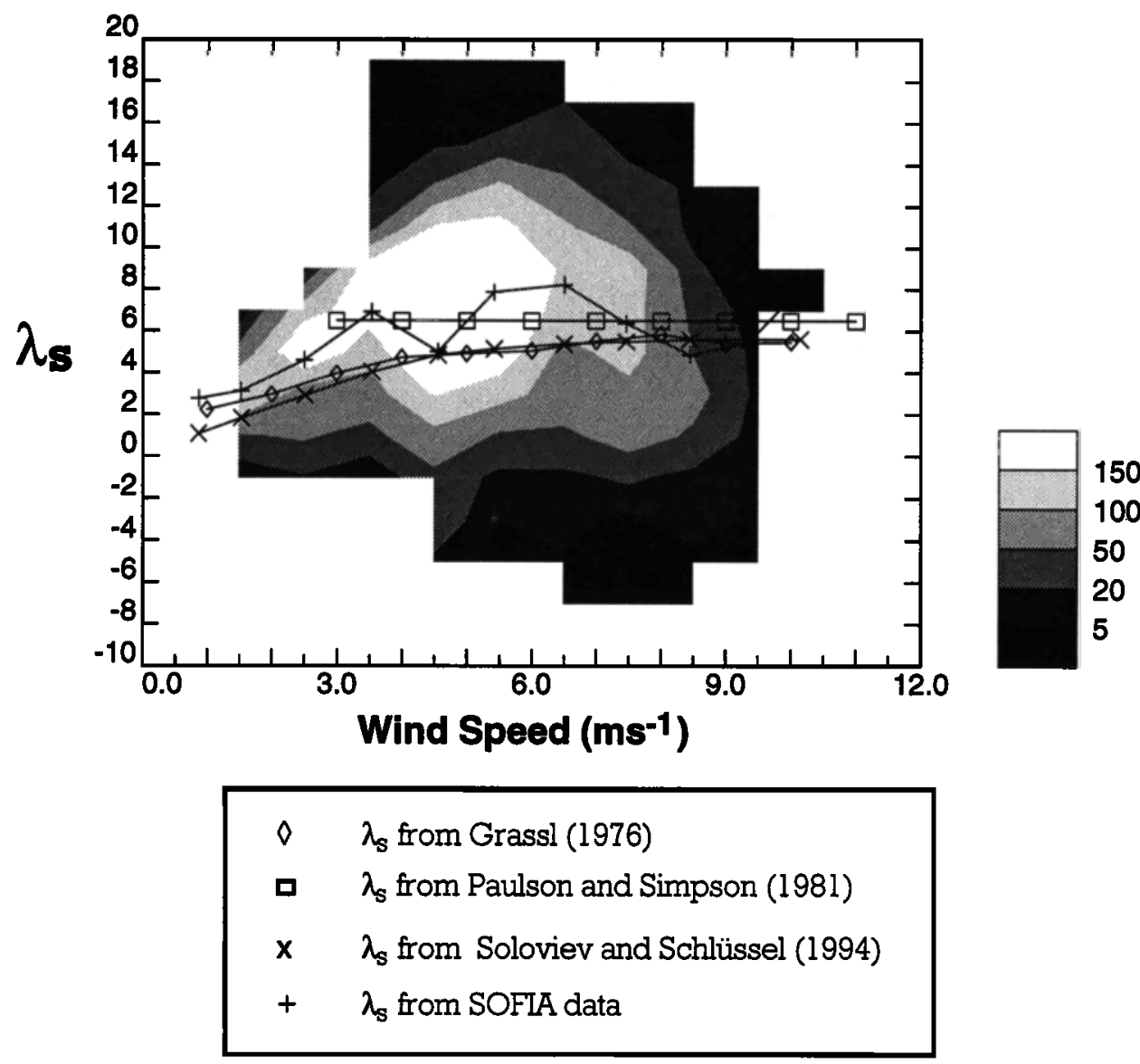

Figure 14. Values for $\lambda_{s}$ in the Saunders formula shown as a function of wind speed. For SOFIA the contours indicate the number of observations in ranges of $1 \mathrm{~m} \mathrm{~s}^{-1}$ wind speed and 2 units of $\lambda_{s}$. Overplotted are the corresponding mean values of $\lambda_{s}$ averaged in $1 \mathrm{~m} \mathrm{~s}^{-1}$ ranges (crosses) and the values for $\lambda_{s}$ calculated for the SOFIA data from the formula of Soloviev and Schliussel [1994] (triangles). The values of $\lambda_{s}$ published by Paulson and Simpson [1981] (diamonds) and Grassl [1976] (squares) are also shown.

also shown in Figure 14. The SOFIA data and the Soloviev formula both showed an increase of $\lambda_{s}$ as the wind speed increased from 1 to $4 \mathrm{~m} \mathrm{~s}^{-1}$. However, the Soloviev values are about half the required value (resulting in the underprediction of the magnitude of $d t$ by Soloviev in light winds). The observational values of Grassl [1976] lie between the Soloviev formula and the SOFIA values. Above $4 \mathrm{~m} \mathrm{~s}^{-1}$ the SOFIA data suggest that $\lambda_{s}=7$ is a reasonable value. Again this value is higher than predicted by Soloviev or observed by Grassl [1976], but it is similar to that observed by Paulson and Simpson [1981]. For comparison, Paulson and Parker [1972] suggested that, for nighttime conditions and an SST of about $15^{\circ} \mathrm{C}$, the Hasse formula implies $\lambda_{s}=8$.

If the models of Saunders (equation (10)) and Hasse (equation (12)) are compared, the differences in the predictions for nighttime data (when the solar term in (12) is zero) should be due to the use of a wind stress by Saunders and wind speed by Hasse. The scatter for the nighttime data at moderate wind speeds for the two parameterizations was similar (Figure 13b), indicating that the use of wind speed does not significantly degrade the prediction. However, the effect of using wind speed rather than wind stress would increase with wind speed and therefore might be more important at wind speeds above those present in this data set.
Finally, we note that the standard deviation of the skin effect (for winds greater than $3 \mathrm{~ms}^{-1}$ ) was $\pm 0.27^{\circ} \mathrm{C}$. In other words, if a constant mean value were to be assumed for the skin effect then the error in the individual skin effect predictions would have that scatter. Compared to the observations, the best of the models achieved a scatter of about $\pm 0.16^{\circ} \mathrm{C}$. This confirms that the better models were showing some skill in predicting the magnitude of the skin effect. This is illustrated in Figure 15 which shows a time series of measured $d t$ along with $d t$ estimated from the Saunders formula for the first leg of the cruise. The coherence between the two time series suggests that the model does perform better than assuming a constant $d t$ value.

\section{Summary and Conclusions}

The data emphasized the need to distinguish between the temperature deviation caused by the ocean surface skin and that due to the formation of a near surface thermocline. Parameterizations which did not include solar radiation effects appeared to best model the surface skin effect observed during the SOFIA experiment. Solar radiation effects were observed only during periods of high solar radiation combined with very light winds, and these could be explained by the presence 


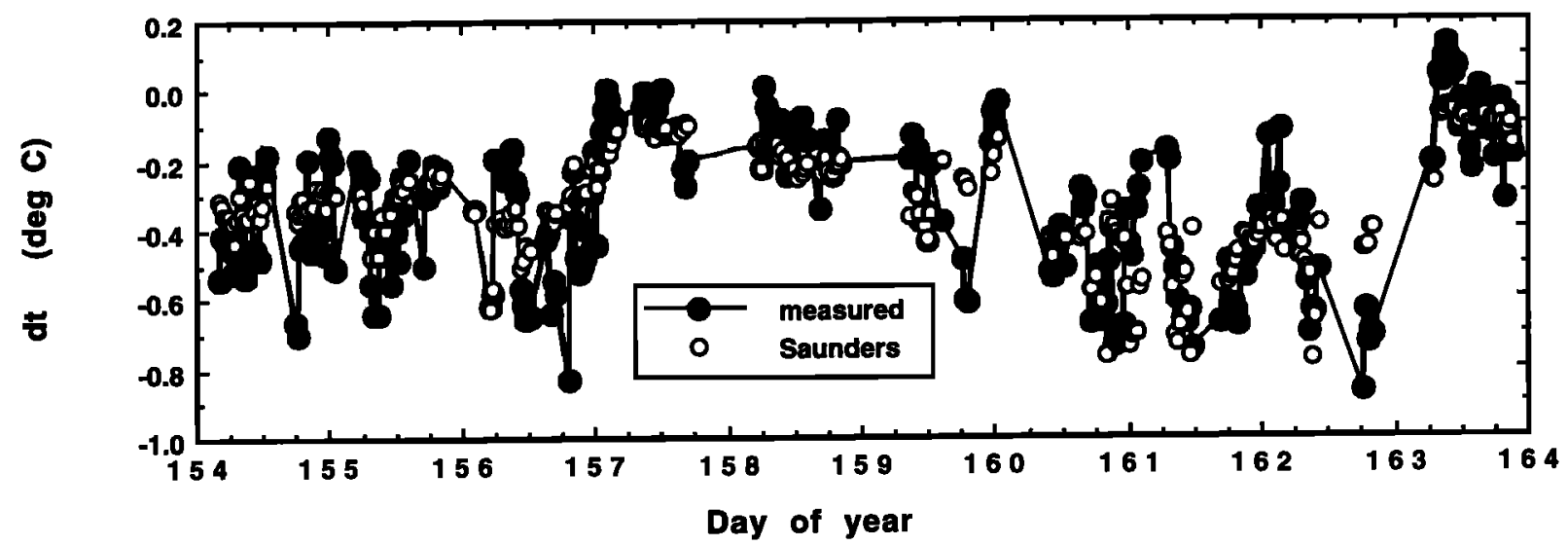

Figure 15. Time series of half-hour averages of measured skin effect, $d t$ (degrees Celsius), and the values predicted from the Saunders formula for the first leg of the SOFIA cruise.

of a near surface thermocline which masked the effect of the surface skin in the measured data. In these cases the apparent skin effect would depend on the history of the surface heating and could not be calculated from the fluxes observed at any given time. Excluding data collected with solar insolation above $800 \mathrm{~W} \mathrm{~m} \mathrm{~m}^{-2}$ and at low wind speeds, there was no noticeable deterioration in predictive quality between nighttime and daytime data for the Saunders and the Soloviev parameterizations which omit solar radiation.

None of the parameterizations performed well at wind speeds below $2 \mathrm{~m} \mathrm{~s}^{-1}$; only values from the Saunders free convection model approached the magnitude of the observed $d t$, and none of the models showed the observed variability. At wind speeds above $7 \mathrm{~m} \mathrm{~s}^{-1}$, the most likely value of the magnitude of the observed skin effect decreased to a value close to zero. At wind speeds between 3 and $7 \mathrm{~m} \mathrm{~s}^{-1}$ the Saunders model best reproduced the observed variation of the skin effect over a range of wind speed, surface cooling, and downward insolation. Over the range of wind speeds observed in this study, it was not possible to determine whether the skin effect correlated better with the wind stress rather than wind speed. The study suggested that the best fit to the SOFIA observations would be a Saunders type model but with the values of $\lambda_{s}$ greater than those predicted by either the Soloviev model or the Grassl [1976] observations.

Acknowledgments. We would like to thank Robin Pascal for technical support for the radiometer and meteorological instruments and Charles Clayson for the radiometer error analysis contained in this paper.

\section{References}

Aksenov, V. N., and G. G. Khundzhua, Absorption of direct infrared solar radiation in the near-surface layer of the ocean, Izv. Acad. Sci. USSR Atmos. Oceanic Phys., Engl. Transl., 22(1), 73-75, 1986.

Brutsaert, W., The roughness length for water vapour, sensible heat, and other scalars, J. Atmos. Sci., 32, 2028-2031, 1975.

Grassl, H., The dependence of the measured cool skin of the ocean on wind stress and total heat flux, Boundary Layer Meteorol., 1, 465474, 1976.

Hasse, L., On the cooling of the sea surface by evaporation and heat exchange, Tellus, 15(4), 363-366, 1963.

Hasse, L., The sea surface temperature deviation and the heat flow at the sea-air interface, Boundary Layer Meteorol., 1, 368-379, 1971.

Henderson-Sellers, A., and P. J. Robinson, Contemporary Climatology, 439 pp., Longman, White Plains, N. Y., 1986.
Hepplewhite, C. L., Radiometric observations of the atmospheric boundary layer (The ROSSA Project), Ph.D. thesis, 219 pp., Univ. of Oxford, Oxford, England, 1989.

Kent, E. C., and R. W. Pascal, Project SOFIA - IOS cruise report, Internal Doc. 7, James Rennell Cent., Southampton, England, 1992.

Khundzhua, G. G., and V. N. Aksenov, On problem of solar radiation absorption by cold ocean film, (in Russian with English abstract), Morsk. Gidrofiz. Zh., 2, 10-14, 1986.

Lind, R. L., and K. B. Katsaros, Radiation budget components and their parameterisation in JASIN, $Q$. J. R. Meteorol. Soc., 110, 1061-1071, 1984.

Liu, W. T., and J. A. Businger, Temperature profile in the molecular sublayer near the interface of fluid in turbulent motion, Geophys. Res. Lett., 2, 403-404, 1975.

Liu, W. T., K. B. Katsaros, and J. A. Businger, Bulk parameterization of air-sea exchanges of heat and water vapour including the molecular constraints at the interface, J. Atmos. Sci., 36, 1722-1735, 1979.

Masuda, K., T. Takashima, and Y. Takayama, Emissivity of pure and sea waters for the model sea surface in the infrared window, Remote Sens. Environ., 24, 313-329, 1988.

Paulson, C. A., and T. W. Parker, Cooling of the water surface by evaporation, radiation, and heat transfer, J. Geophys. Res., 77, 491495, 1972.

Paulson, C. A., and J. J. Simpson, Irradiance measurements in the upper ocean, J. Phys. Oceanogr., 7, 952-956, 1977.

Paulson, C. A., and J. J. Simpson, The temperature difference across the cool skin of the ocean, J. Geophys. Res., 86, 11044-11054, 1981.

Payne, R. E., Albedo of the sea surface, J. Atmos. Sci., 29, 959-970, 1972.

Price, J. F., R. A. Weller, C. M. Bowers, and M. G. Briscoe, Diumal response of sea surface temperature observed in the long-term upper ocean study $\left(34^{\circ} \mathrm{N}, 70^{\circ} \mathrm{W}\right)$ in the Sargasso Sea, J. Geophys. Res., 92 , 14480-14490, 1987.

Ray, P. S., Broadband complex refractive indices of ice and water, Appl. Opt., $11,1836-1843,1972$.

Robinson, I. S., N. C. Wells, and H. Charnock, The sea surface thermal boundary layer and its relevance to the measurements of sea surface temperature by airborne and spacebome radiometers, Int. J. Remote Sens., 5, 19-45, 1984.

Saunders, P. M., The temperature at the ocean-air interface, J. Atmos. Sci., 24, 269-273, 1967.

Saunders, P. M., The skin temperature of the ocean: A review, Mém. Soc. R. Sci. Liege, 6, 93 - 98, 1973.

Schlüssel, P., W. J. Emery, H. Grassl, and T. Mammen, On the bulk-skin temperature difference and its impact on satellite remote sensing of sea surface temperature, J. Geophys. Res., 95, 13341-13356, 1990.

Smith, N. P., Radiometer Type STR100-2 Users Manual, 38 pp., Satellites International, Newbury, England, 1991.

Smith, S. D., Coefficients for sea surface wind stress, heat flux and wind profiles as a function of wind speed and temperature, J. Geophys. Res., 93, 15467-15474, 1988.

Smith, S. D., Water vapour flux at the sea surface, Boundary Layer Meteorol, , 47, 277-293, 1989. 
Soloviev, A. V., and P. Schlüssel, Parameterisation of the cool skin of the ocean and of the air-ocean gas transfer on the basis of modelling surface renewal, J. Phys. Oceanogr., 24, 1339-1346, 1994.

Thomas, J. P., R. J. Knight, H. K. Roscoe, J. Turner, and C. Symon, An evaluation of a self-calibrating infrared radiometer for measuring sea surface temperature, J. Atmos. Oceanic Technol., 12(2), 301316, 1995.

Zavody, A. M., C. T. Mutlow and D. T. Llewellyn-Jones, A radiative transfer model for sea surface temperature retrieval for the along track scanning radiometer, J. Geophys. Res., 100, 937-952, 1995
T. N. Forrester, E. C. Kent, and P. K. Taylor, James Rennell Division, Southampton Oceanography Centre, European Way, Southampton SO14 3ZH, England. (elizabeth.kent@soc.soton.ac.uk)

(Received May 8, 1995; revised January 4, 1996; accepted March 12, 1996.) 